\title{
Zebrafish Models of Craniofacial Malformations: Interactions of Environmental Factors
}

\author{
S. T. Raterman ${ }^{1,2,3}$, J. R. Metz ${ }^{3}$, Frank A. D. T. G. Wagener ${ }^{1,2}$ and \\ Johannes W. Von den Hoff1,2* \\ ${ }^{1}$ Radboud Institute of Molecular Life Sciences, Nijmegen, Netherlands, ${ }^{2}$ Department of Dentistry-Orthodontics \\ and Craniofacial Biology, Radboud University Medical Center, Nijmegen, Netherlands, ${ }^{3}$ Department of Animal Ecology \\ and Physiology, Institute for Water and Wetland Research, Radboud University, Nijmegen, Netherlands
}

OPEN ACCESS

Edited by:

Erika Kuchler,

Universidade Positivo, Brazil

Reviewed by:

Sabrina Kathrin Schulze, University of Potsdam, Germany Patricia Tannure,

Veiga de Almeida University, Brazil

${ }^{*}$ Correspondence:

Johannes W. Von den Hoff hans.vondenhoff@radboudumc.nl;

h.vondenhoff@dent.umcn.nl

Specialty section:

This article was submitted to

Cell Growth and Division,

a section of the journal

Frontiers in Cell and Developmental

Biology

Received: 31 August 2020

Accepted: 23 October 2020

Published: 16 November 2020

Citation:

Raterman ST, Metz JR,

Wagener FADTG and

Von den Hoff JW (2020) Zebrafish Models of Craniofacial Malformations: Interactions of Environmental Factors. Front. Cell Dev. Biol. 8:600926. doi: 10.3389/fcell.2020.600926
The zebrafish is an appealing model organism for investigating the genetic (G) and environmental (E) factors, as well as their interactions (GXE), which contribute to craniofacial malformations. Here, we review zebrafish studies on environmental factors involved in the etiology of craniofacial malformations in humans including maternal smoking, alcohol consumption, nutrition and drug use. As an example, we focus on the (cleft) palate, for which the zebrafish ethmoid plate is a good model. This review highlights the importance of investigating ExE interactions and discusses the variable effects of exposure to environmental factors on craniofacial development depending on dosage, exposure time and developmental stage. Zebrafish also promise to be a good tool to study novel craniofacial teratogens and toxin mixtures. Lastly, we discuss the handful of studies on gene-alcohol interactions using mutant sensitivity screens and reverse genetic techniques. We expect that studies addressing complex interactions (ExE and GxE) in craniofacial malformations will increase in the coming years. These are likely to uncover currently unknown mechanisms with implications for the prevention of craniofacial malformations. The zebrafish appears to be an excellent complementary model with high translational value to study these complex interactions.

Keywords: zebrafish, craniofacial malformations, neural crest cells, environment, gene, interaction

\section{INTRODUCTION}

Craniofacial malformations are a heterogenic group of developmental defects of the skull and face, for which no preventive therapies exist. This broad group of over 700 disorders includes debilitating malformations of the skull (craniosynostosis), jaw (micrognathia), face (hemifacial microsomia, deformational plagiocephaly) and teeth (tooth agenesis), (Online Mendelian Inheritance in

\footnotetext{
Abbreviations: AhR, Aryl hydrocarbon receptor; BMP, Bone morphogenetic protein; BPA/AF/S/F, Bisphenol A/AF/S/F; CDC, Center for disease control; CLP, Cleft lip and/or palate; CNCC, Cranial neural crest cells; CYP1A, Cytochrome P450 1A; DHODH, Dihydroorotate dehydrogenase; dpf, Days post fertilization; E2, 17ß-estradiol; ENU, N-ethyl-n-nitrosourea; ER, Estrogen receptors; FA, Follic acid; FAS, Fetal alcohol syndrome; FASD, Fetal alcohol spectrum disorders; FDA, Food and drug administration; FGF, Fibroblast growth factor; FVSP, Fetal valproate spectrum disorder; GST, Glutathione-S-transferase; GWAS, Genome wide association studies; hpf, Hours post fertilization; M-PQ, Meckel's-palatoquadrate; OMIM, Online Mendelian Inheritance in Man; OR, Odds ratio; PAH, Polycyclic aromatic hydrocarbons; RA, Retinoic acid signaling; SHH, Sonic hedgehog; TGF, Transforming growth factor; TPM, Total particular matter; VPA, Valproic acid; WHO, World health organization; WNT, Wingless-Int-1 pathway.
} 
Man) (OMIM). Heterogeneity is not only a principal feature of craniofacial phenotypes, but also contributes to their etiology, as malformations are often caused by complex interactions of genetic and environmental factors (Gardner et al., 1998; Dixon et al., 2011).

In this review, we focus on clefts of the palate, which oftentimes co-occur with cleft lip. Cleft lip and/or palate (CLP) is the most common congenital craniofacial birth defect. It affects the face uni- or bilaterally, as well as the hard and soft palate (Dixon et al., 2011). Extensive reconstructive surgery and dental treatment are often required until adulthood for the various forms of CLP (Acum et al., 2020; Martin et al., 2020). After surgery, CLP patients may still experience difficulties with speaking and hearing, leading to psychosocial problems (Martin et al., 2020). About 30\% of CLP cases arise as part of a syndrome caused by a single genetic mutation. However, the majority of cases are non-syndromic and associated with both genetic $(G)$ and environmental (E) risk factors (Beaty et al., 2011; Dixon et al., 2011; Stuppia et al., 2011).

Candidate genes for CLP are continually identified benefiting from genetic data from individuals, family-and-twin studies, and large-scale GWAS studies (Beaty et al., 2002; Mansilla et al., 2005; Leslie et al., 2015). Often, these genes relate to central regulatory pathways of development including sonic hedgehog (SHH), transforming growth factor (TGF), fibroblast growth factor (FGF), bone morphogenetic protein (BMP), retinoic acid signaling (RA) and Wingless-Int-1 pathway (WNT) signaling (Beaty et al., 2011; Dixon et al., 2011; Reynolds et al., 2019). For example, mutations of the BMP pathway gene MSX1 and multiple canonical (WNT9B) and non-canonical (WNT5A) WNT pathway genes have been associated with non-syndromic CLP (Chiquet et al., 2008). In parallel, environmental factors such as smoking, drinking, drug use, diet and other lifestyle habits during pregnancy have been demonstrated to increase the risk of CLP (van Rooij et al., 2001; DeRoo et al., 2008; Jentink et al., 2010) and other craniofacial malformations (Gardner et al., 1998; Carmichael et al., 2008; Al-Ani et al., 2017). Due to the substantial number of factors involved in craniofacial malformations, the underlying etiology remains largely elusive. Moreover, interactions between genetic and environmental factors $(\mathrm{GxE})$ further complicate the etiology. Since no single animal model can mimic all facets of genetic and environmental influences on craniofacial development in humans, the use of multiple model species is required to elucidate the etiology of craniofacial malformations.

Zebrafish are a promising model to study both genetic and environmental interactions in craniofacial malformations, such as palatal clefts. In the last decade, there has been a rapid increase in zebrafish genetic models for human disease-causing genes including CLP (reviewed by Duncan et al., 2017; Machado and Eames, 2017). Additionally, the growing zebrafish-based research field investigating the role of environmental factors in craniofacial malformations enhances the value of zebrafish in craniofacial research. Zebrafish studies have produced powerful mechanistic insights on both the genetic (variants) and environmental factors which disturb facial development. Up to now, investigations of $\mathrm{GxE}$ interactions are published less frequently. However, zebrafish studies in this field are upcoming since there is overwhelming evidence that $\mathrm{GxE}$ interactions are the crux of cleft etiology in humans (Wu et al., 2010; Beaty et al., 2011; Dixon et al., 2011; Stuppia et al., 2011).

We have outlined this review as follows: first we discuss zebrafish studies on the effects of maternal smoking, alcohol use, nutrition, drug use and household environmental factors on craniofacial development. We specifically focus on the molecular mechanisms and phenotypic outcomes. Environmental factors with the highest odds ratio (OR) for incidence of craniofacial malformations are discussed first. Secondly, we consider the limited but emerging field of $\mathrm{GxE}$ interactions in zebrafish models for craniofacial malformations, and propose strategies for future research.

\section{ZEBRAFISH AS A CRANIOFACIAL MODEL SYSTEM}

The teleost fish, the zebrafish has several advantages over the use of other vertebrate animal models for the study of congenital defects. In particular, zebrafish has a rapid, transparent early development and large brood sizes (Schilling and Kimmel, 1997). They develop a detailed and visible craniofacial skeleton as early as 5 days post fertilization (dpf) (Kimmel et al., 2001). Zebrafish embryos can also be directly exposed to environmental factors via the embryo medium. Zebrafish orthologous genes have been identified for $82 \%$ of disease-causing genes in humans as reported in OMIM (Howe et al., 2013). These assets make the zebrafish an attractive model for studying early craniofacial development alongside more traditional animal models such as mouse and chicken (Van Otterloo et al., 2016).

In zebrafish, craniofacial development commences with the migration of cells from the rhombomeres and mesencephalon of the neural crest. These cells migrate in tightly regulated lineages toward predetermined destinations in the head region (Dougherty et al., 2012; Rocha et al., 2020). The first lineage of cranial neural crest cells (CNCC) splits and one part migrates between the developing eyes making up the frontonasal CNCCs. The other part migrates ventrally to populate the first of seven pharyngeal arches (Wada et al., 2005; Swartz et al., 2011; Dougherty et al., 2012). Arches 2-7 are subsequently populated by other lineage of CNCCs, where, upon arrival, all CNCCs surround a mesoderm core (Mork and Crump, 2015). Orchestrated by evolutionary conserved intrinsic and extrinsic signaling, the CNCCs condense and undergo chondrogenic differentiation to form the head cartilages. Comprehensive data and resources on craniofacial development can be found at FaceBase ${ }^{1}$, including "FishFace, an atlas of zebrafish craniofacial development" (Eames et al., 2013).

As mentioned, zebrafish develop a functional craniofacial skeleton within the first 5 days post fertilization (Figure 1). However, the zebrafish craniofacial skeleton is structurally more complex than that of most other vertebrates, and continues to grow throughout the fish's lifetime (Bruneel and Witten,

\footnotetext{
${ }^{1}$ www.facebase.org/
} 

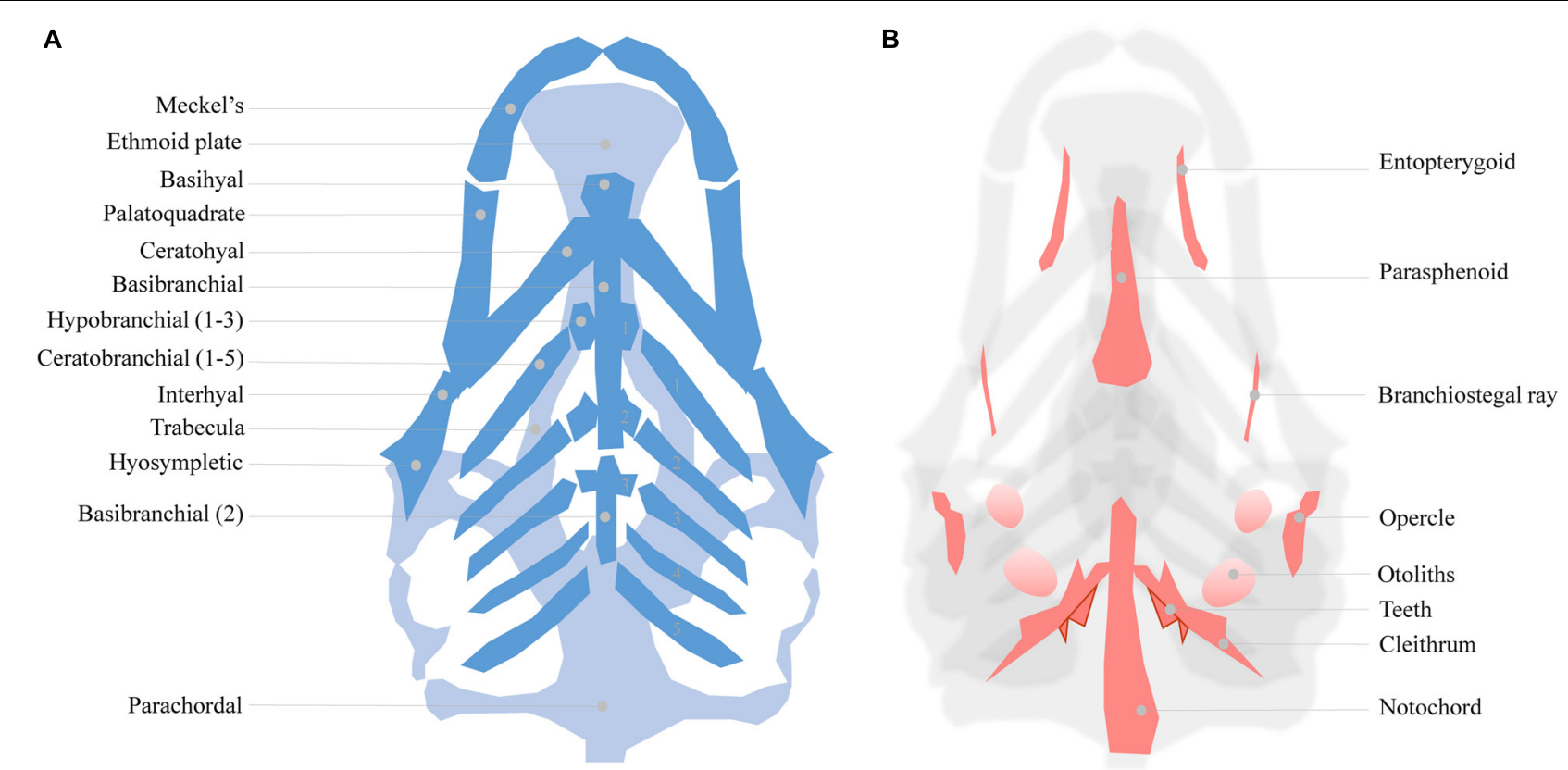

FIGURE 1 | (A) Cartilage structures of the zebrafish neuro- and viscerocranium at $5 \mathrm{dpf}$ (light and dark blue, respectively), ventral perspective. A number of these structures is used as a homolog to human skeletal features: Meckel's cartilage for the lower jaw, the ethmoid plate for the hard palate and the palatoquadrate for the middle ear. (B) Intramembranous bones of the 5 dpf zebrafish head, dorsal view.

2015). The adult zebrafish head contains 73 bones, exceeding the number of bones in the mammalian skull at least three fold (Cubbage and Mabee, 1996). The early cartilage structures consist of only a few chondrocyte and perichondral cell layers (Figure 1A; Kimmel et al., 2001). The first cartilages can be detected as early as $3 \mathrm{dpf}$, while some intramembranous bone structures also start to form on the cartilage matrix (Aceto et al., 2015). At $5 \mathrm{dpf}$, a small number of bone structures are already present (detailed in Figure 1B). The cartilages are divided into the dorsally located neurocranial structures (CNCC- and mesoderm- derived) that support the developing brain, and the ventrally located pharyngeal arch-derived structures important for feeding and gill coverage (Kimmel et al., 2010). The cartilages are maintained during early larval stages and are progressively replaced by bone through endochondral ossification (Cubbage and Mabee, 1996; Bruneel and Witten, 2015; Weigele and FranzOdendaal, 2016). Surprisingly, the zebrafish intramembranous bones are often disregarded in investigations of craniofacial development in the presence of environmental factors, resulting in significant knowledge gaps.

The zebrafish larval head can be used to study various craniofacial malformations. For instance, the cranial sutures of the juvenile (3-12 weeks) zebrafish skull can be manipulated to mimic craniosynostosis, while the Meckel's cartilage formation can be used study lower jaw defects (Miller et al., 2000; Andreeva et al., 2011; Laue et al., 2011; Cornille et al., 2019). To be concise, we focus on the ethmoid plate and the associated trabecula. These structures are part of the zebrafish neurocranium and are considered homologous to the mammalian palate (Bush and Jiang, 2012).
The ethmoid plate and the mammalian hard palate both derive from bilateral streams of anterior maxillary CNCC (Mork and Crump, 2015). In zebrafish, frontonasal CNCCs migrate below the eyes to the midline, while maxillary CNCCs from the first pharyngeal arch assemble laterally to the midline. Then, both lineages fuse to form the ethmoid plate (Dougherty et al., 2013). In humans, mice and, other mammals, the palate develops during gestational weeks 6-12 (humans) and E10-E16 (mice) (Bush and Jiang, 2012). The palate emanates from the outgrowth, vertical-to-horizontal reorientation and fusion of CNCC-derived maxillary prominences (Bush and Jiang, 2012). Mutations in PDGFRA and genes of the SHH pathway lead to inadequate midline fusion resulting in a cleft palate phenotype in mice, humans and zebrafish (Wada et al., 2005; Swartz et al., 2011; Dougherty et al., 2013; McCarthy et al., 2013). These shared disease etiologies confirm that similar molecular mechanisms are involved in the development of the palate and ethmoid plate. A commonly accepted interpretation hereof is that the ethmoid plate is homologous to the mammalian palate (Mork and Crump, 2015). In zebrafish, the cleft phenotype typically features aberrant chondrocyte morphology and stacking in the ethmoid plate. Also, the anterior border of the ethmoid plate can appear dented instead of smooth. More severe ethmoid phenotypes include two anteriorly unconnected outer rods or only a single rod. The spectrum of ethmoid plate disruptions is broad, but some representative examples taken from the literature on environmental factors are represented in Figure 2.

Additional morphological, cellular and molecular parallels between mammals and zebrafish are continually identified in craniofacial research. Virtually every new discovery further 
A
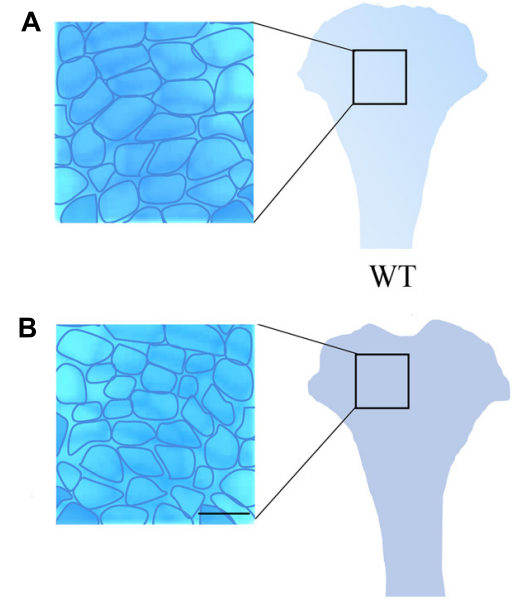

Treatment

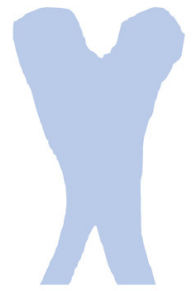

Dexamethasone $200 \mu \mathrm{M}$

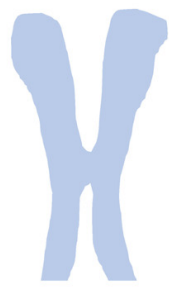

$30 \%$ hypoxia

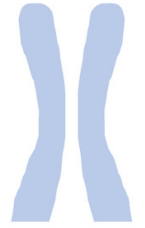

$50 \%$ hypoxia

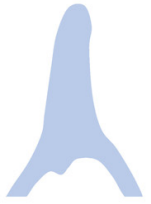

Retinoic acid $5 \mathrm{nM}$

FIGURE 2 | (A) Wildtype ethmoid plate with associated stacking of chondrocytes. (B) Redrawn examples of ethmoid plate defects observed in zebrafish environmental factor exposure studies (Kuchler et al., 2018; Liu et al., 2020) (Methotrexate $100 \mu$ M, Dexamethasone $200 \mu$ M, retinoic acid 5 nM and hypoxia). A broad phenotypic range of ethmoid plate defects is observed, indicating that development of the ethmoid plate is affected variously by different compounds. Mild phenotypes include a rough edge to the anterior ethmoid plate, and differential cell morphology (round vs. elongated) and chondrocyte stacking is disordered, drawn from Liu et al. (2020) (scale bar $5 \mu \mathrm{m}$ ). At the other end of the spectrum, phenotypes are observed in which ethmoid plate structures are (partially) missing, indicating effects on migration, differentiation and survival CNCCs. Moreover, some factors affect early as well as late craniofacial development, and various effects can occur though differential exposure times during specific sensitivity windows.

supports the translational value of the zebrafish model. We advocate that zebrafish should be used more extensively as an additional tool complementary to established models such as the mouse. In the following sections, we discuss zebrafish models for investigating environmental factors in craniofacial malformations.

\section{SMOKING}

In epidemiological studies, maternal smoking before and during early pregnancy is consistently reported as an environmental risk factor for CLP (Stuppia et al., 2011; Sabbagh et al., 2015; Xuan et al., 2016). Despite decades of research, the mechanisms by which smoking affects development are still not fully understood. Since cigarette smoke consists of over 7,000 components, numerous mechanisms are involved (center for disease control) $(\mathrm{CDC})^{2}$. Abundant components of smoke are polycyclic aromatic hydrocarbons (PAHs), carbon monoxide, tar and nicotine (Kennedy et al., 2017). These compounds can exert direct teratogenic effects when transported across the placenta to the amniotic fluid (Liszewski et al., 2012). Cigarette smoke contains inhibitors (nicotine) and inducers (PAH) of the aryl hydrocarbon receptor (AhR) pathway that activates cytochrome P450 1A (CYP1A). During xenobiotic metabolism, reactive products are formed from PAHs, mediated by CYP1A. These products can cause cell damage if they are not rapidly detoxified by metabolite glutathione-S-transferase (GST). Activity of this enzyme can be reduced by smoke itself or by genetic factors (van

${ }^{2}$ https://www.cdc.gov/biomonitoring/tobacco.html
Rooij et al., 2001). For instance, a maternal GSTT1-null genotype in humans has been shown to increase the risk of clefting in the offspring of smoking mothers (odds ratio 3.2) (van Rooij et al., 2001). Thus, the toxicity of smoking can be further increased by genetic predisposition for suboptimal function of the enzymes for xenobiotic metabolism.

In studies on the effects of maternal smoking on development, zebrafish were traditionally used as a model to examine effects of single abundant compounds of cigarette smoke. Craniofacial malformations are consistently reported in zebrafish studies on smoke compounds such as PAHs, carbon monoxide (hypoxia) and nicotine (Billiard et al., 2006; Parker and Connaughton, 2007; Geier et al., 2018; Kuchler et al., 2018). Specifically, clefts in the ethmoid plate were observed when zebrafish are exposed to hypoxic conditions during early development. These clefts increased in severity as oxygen levels were reduced (Kuchler et al., 2018). Although single-factor investigations are interesting from a fundamental standpoint, they do not provide clinically relevant insights on the effects of maternal smoking on development, because the combined teratogenic effects of smoke compounds may be additive.

In recent years, there has been an increasing amount of literature on the effects of smoke on zebrafish development by exposure to the total particular matter (TPM) of cigarette smoke. TPM exposure lead to craniofacial malformations from above $6 \mu \mathrm{g} / \mathrm{mL}$, but craniofacial malformations have not yet been evaluated in depth (Ellis et al., 2014; Massarsky et al., 2015; Palpant et al., 2015). Other reported effects of TPM are increased larval mortality, gross morphological deformities and distorted AhR pathway-related enzyme functions (CYP1A and GST). Cross-talk between the AhR pathway and Wnt/ $/$-catenin 
signaling in zebrafish embryos was also shown. Wnt/ $\beta$-catenin signaling is a major pathway in craniofacial development (Zhang et al., 2016; Reynolds et al., 2019). Moreover, AhR activation down-regulated sox9a during cartilage formation in zebrafish (Xiong et al., 2008). Knockdown of the AhR pathway with simultaneous exposure to TPM reduced morphological defects, however knockdown of CYP1A or CYP1B1 increased defects (Massarsky et al., 2016). This confirms that the toxicity of TPM is partly dependent on the genetic factors controlling xenobiotic metabolism. Predictably, the overall teratogenic effects of TPM on zebrafish larvae were not mimicked by nicotine alone (Massarsky et al., 2015). This exemplifies the importance of evaluating compound interactions.

With the emergence of the e-cigarette, new risk factors for congenital malformations were introduced. Studies show that e-cigarettes are regarded by pregnant women as a safer alternative for tobacco during pregnancy (Wagner et al., 2017). The compounds in e-cigarette liquids differ considerably from regular cigarettes as the main components are nicotine, propylene glycerol and vegetable glycerin (the latter two account for 90\% of the content) (Schober et al., 2014). Upon partial combustion of propylene glycerol and vegetable glycerin, toxins such as formaldehyde, acrolein, benzene and reactive aldehydes form, that may pose a health risk (Schober et al., 2014). Zebrafish exposed to low levels of propylene glycerol $(1.25,2.5$, or $5 \%$, at $6-$ $72 \mathrm{hpf}$ ) showed disrupted development, including cardiac defects and morphological malformations (Massarsky et al., 2017). It is concerning that such e-cigarette components are new widespread environmental factors that pregnant women are exposed to.

In e-cigarettes, a vast number of chemicals is also used to add optional flavors. Already, over 7,000 different flavors were on the market in 2014 (Zhu et al., 2014). Flavor ingredients are not listed by manufacturers, possibly because this is not required by law (Tierney et al., 2016). Zebrafish have previously been exposed to fruit flavored e-liquids containing the active compounds ethyl vanillin, maltol and vanillin. It was reported that this caused developmental defects including unspecified craniofacial malformations (Tierney et al., 2016; Holden et al., 2020). The combustion of "berry" and "cream" flavors appeared to cause craniofacial malformations more frequently, but the chemical composition of these (and most other) e-cigarette flavors is unknown. In Xenopus, e-cigarette flavors caused craniofacial defects, which were enhanced by co-exposure to nicotine. On its own, nicotine caused only minor malformations (Kennedy et al., 2017). These data confirm interactions between components of e-cigarette liquids and emphasize the need for combined TPM exposure studies. While some e-cigarette flavors have been studied in zebrafish and other animals, considerably more investigations are needed on their interactions and mechanisms of action.

\section{ALCOHOL}

Fetal alcohol syndrome (FAS) and fetal alcohol spectrum disorders (FASD) are pressing health conditions resulting from alcohol exposure during the first two trimesters of pregnancy.
FAS (0.2-1.5 in 1,000 births) describes a multitude of congenital abnormalities of the nervous system, cardiovascular system and face. FASD (1-5 in 100 births) symptoms are less severe but also include central nervous system disorders and craniofacial malformations ${ }^{3}$. The variety in symptoms upon alcohol exposure can be attributed to factors including the timing of alcohol exposure, dosage, metabolism and epigenetics (McCarthy and Eberhart, 2014). Described craniofacial malformations include a flat midface (midface hypoplasia), short nose and smooth philtrum, a thin upper lip, microcephaly, micrognathia and, in $7 \%$ of FASD cases, cleft palate (Sampson et al., 1997; Li et al., 2007). Ethanol exposure and FAS/FASD etiology have received ample attention in zebrafish studies and other models, and studies are reviewed frequently (McCarthy and Eberhart, 2014; Facciol et al., 2019; Lovely, 2020).

Ethanol can be found in amniotic fluid after alcohol consumption by the mother and can thus impact the fetus directly. Within $1 \mathrm{~h}$ after consumption, fetal alcohol levels are equivalent to those in the maternal circulation (Burd et al., 2007). The known mechanisms of ethanol teratogenicity are many fold. Currently, they are known to include increased cell death, reactive oxygen species, altered growth factor signaling, altered retinoic acid signaling, disrupted cholesterol homeostasis and impaired cell adhesion (Li et al., 2007; Marrs et al., 2010; Soares et al., 2012; Sarmah et al., 2013; Muralidharan et al., 2015; Eason et al., 2017). The zebrafish is an established model to study the effects of ethanol on development. Importantly, the chorion, which surrounds the early zebrafish embryo, appears freely permeable for ethanol. Zebrafish embryonic ethanol levels reach approximately $25-35 \%$ of the embryo medium level (Blader and Strahle, 1998; Ali et al., 2011; Fernandes et al., 2019). In zebrafish, both short-term and chronic ethanol exposure increase the incidence of craniofacial malformations.

In search of ethanol sensitivity windows for craniofacial development, zebrafish embryos were exposed to a-rather extreme-regime of $10 \%$ ethanol during defined developmental stages (Ali et al., 2011). At 25 and 31 hpf (developmental stages prim-6 and prim-16, respectively) embryos were most susceptible to defects of the branchial arches and Meckel's cartilage (Ali et al., 2011). Furthermore, in the late blastula and early gastrula stages, embryos appeared to be specifically sensitive for the induction of cyclopia after exposure to $2.4 \%$ ethanol (Blader and Strahle, 1998). Upon chronic exposure, distinct craniofacial effects have been observed depending on ethanol dosage. Ethmoid plate development and head width were reduced at concentrations as low as $3 \mathrm{mM}(0.01 \%)$, which can be reached in women upon drinking only one alcoholic beverage (Carvan et al., 2004; Ferdous et al., 2017). Interestingly, with rising concentrations, a sensitivity shift was reported. At $10 \mathrm{mM}$ ethanol $(0.04 \%)$, neurocranium structures were more severely affected than structures of the viscerocranium, while at $30 \mathrm{mM}(0.13 \%)$ the opposite was observed (Carvan et al., 2004). Variations in sensitivity to ethanol exposure between zebrafish strains are also reported. Upon exposure, Ekkwill strain zebrafish presented with a severely affected viscerocranium

\footnotetext{
${ }^{3}$ www.cdc.gov/ncbddd/fasd/data.html
} 
and increased apoptosis, whereas $\mathrm{AB}$ strain zebrafish had affected neurocranial cartilages such as the ethmoid plate. In Tübingen strain zebrafish larvae a high mortality rate was observed, but this strain was less prone to craniofacial defects (Loucks and Carvan, 2004). The strain specific sensitivity to ethanol implicates that predisposing genetic factors and GxE interactions are involved.

Most studies in which zebrafish were exposed to ethanol, used the timeframe between 6 and $24 \mathrm{hpf}$. This is equivalent to binge drinking (4-5 drinks) throughout the entire first trimester of pregnancy in humans. This poorly resembles a clinically relevant situation and, therefore, Zhang et al. transiently exposed zebrafish to alcohol, during early gastrulation (5.25$6.25 \mathrm{hpf}$ ) and neurulation (8-10 and 24-27 hpf) (Zhang et al., 2014). These larvae presented with FASD symptoms, including craniofacial malformations and differential expression of $\mathrm{SHH}$ pathway genes. Interaction with $\mathrm{SHH}$ signaling seems to be a central mechanism of ethanol teratogenicity (Li et al., 2007; Burton et al., 2017). Upon translation, Shh undergoes posttranslational modifications by cholesterol. This mechanism is crucial for craniofacial development, but ethanol (0.7-7 $\mathrm{mM})$ treatment during gastrulation impaired modification of shh by cholesterol (Li et al., 2007). As previously mentioned, $\mathrm{SHH}$ pathway gene mutations are also implicated in craniofacial malformations in humans. Later in this review we will discuss evidence of interactions between genetic factors and ethanol, which further complicates the mechanism of action.

\section{VITAMINS AND EXE INTERACTIONS}

Proper development requires a delicate balance of micronutrients. Specifically, derivatives of vitamins $\mathrm{A}$ and $B$ are crucial for craniofacial development in both fish and mammals. Zebrafish have been used to study the roles of vitamins $\mathrm{A}$ and $\mathrm{B}$ during development and in craniofacial malformations. Far less is currently known from the zebrafish model about other essential vitamins and trace elements implicated in craniofacial malformations.

\section{Vitamin A}

Retinoic acid (RA) is a vitamin A-derived retinol and an essential morphogen in embryonic development. Vitamin A is acquired through products such as meat, milk, eggs and carrots (Metzler and Sandell, 2016). Vitamin A deficiency (serum level $<0.70 \mu \mathrm{mol} / \mathrm{L}$ ) is a public health concern in countries in Africa and South East Asia, and was associated with craniofacial malformations including $\mathrm{CLP}\left(\mathrm{WHO}^{4}\right)$ (Ackermans et al., 2011; Mammadova et al., 2014; Metzler and Sandell, 2016; Williams and Bohnsack, 2019). Supplementation with vitamin A was associated with a lower cleft risk $(\mathrm{OR}=0.48)$ (Johansen et al., 2008). Use of acne medication that contains vitamin A derivatives during pregnancy may result in hypervitaminosis A. This increased the risk of craniofacial malformations including

${ }^{4}$ www.who.int/elena/titles/vitamina_pregnancy/en/ cleft lip, cleft palate, micrognathia and midface hypoplasia (Williams and Bohnsack, 2019).

In mammals, RA precursors are delivered to the fetus by the maternal circulation in the form of retinoids and carotenoids. In zebrafish, RA is synthesized by oxidation of all-transretinal derived from the yolk (Metzler and Sandell, 2016). RA subsequently acts through the nuclear retinoic acid receptors. These receptors belong to the steroid/thyroid superfamily (Joore et al., 1994; Metzler and Sandell, 2016). Zebrafish have two $(\alpha$ and $\gamma$ ) RA receptors while mammals have three $(\alpha, \gamma$, and $\beta)$. Retinoic acid receptors are widely expressed throughout the embryo and act by dimerization with retinoid $\mathrm{x}$ receptors. Active RA is degraded by CYP26A1 and CYP26B1, and a posterioranterior increasing gradient of RA is maintained during early development (Williams and Bohnsack, 2019).

RA is a key regulator of Hox-family genes, which are essential for pharyngeal arch development (Williams and Bohnsack, 2019). RA targets the endoderm and ectoderm surrounding the CNCCs, which subsequently signal to CNCCs in the pharyngeal arches. In zebrafish, $1 \mathrm{nM}$ of exogenous RA between 10.5 and 12.5 hpf increased expression of the hoxal and hoxb2 genes. This resulted in the fusion of structures of the first and second pharyngeal arches, such as fusion of the ceratohyal cartilage with Meckel's cartilage (Yan et al., 1998). Moreover, transient treatment with $1 \mu \mathrm{M}$ RA during gastrulation (5.25-10 hpf) resulted in complete loss of expression of the neural crest cell marker $d l x$ in the head at $24 \mathrm{hpf}$, and the absence of craniofacial cartilages. At $0.1 \mu \mathrm{M}$ RA, $d l x$ expression was detected in neurocranial structures, but not in the viscerocranium, suggesting specific sensitivity of these structures (Ellies et al., 1997). Embryos treated with $0.1 \mu \mathrm{M}$ RA during neural crest migration (12-19 hpf) showed impaired Meckel's cartilage and palatoquadrate formation, which was also associated with reduced dlx4 expression. RA treatment caused only mild effects on Meckel's cartilage upon treatment at $24 \mathrm{hpf}$, suggesting RA mainly affected CNCC migration (Ellies et al., 1997). In contrast to these findings, at a much lower concentration (5 $\mathrm{nM}$ ) and using continual exposure between 4 and $96 \mathrm{hpf}$, exogenous RA had severe effects on the neurocranium. The ethmoid plate was reportedly severely shortened and resembled a single rod. Cells of the ethmoid plate were also disorderly stacked (Liu et al., 2020). After development, RA retains essential functions in regulating osteoblast and osteoclast activity, maintaining bone mineral density, and promoting cell survival (Williams and Bohnsack, 2019). Exogenous RA treatment (0.1 $\mu \mathrm{M})$ in adult zebrafish during just 5 days resulted in an acute prognathic jaw. Inhibition of RA synthesis resulted in decreased head height (Chawla et al., 2018). Similarly, craniosynostosis phenotypes were observed in CYP26b (hypomorph)-deficient juvenile zebrafish as a result of disrupted RA degradation (Spoorendonk et al., 2008; Laue et al., 2011). These data support that a tight regulation of RA activity is necessary during and after craniofacial development.

Epidemiological studies showed that the risk of FASD and craniofacial malformation were higher in pregnancies with alcohol exposure in low socioeconomic environments. In these environments, maternal malnutrition and vitamin (A) deficiency 
are more frequent (Jiang et al., 2020). Ethanol competes with retinol for a dehydrogenase that converts retinol into RA and ethanol into acetaldehyde (Marrs et al., 2010). In zebrafish, RA and ethanol appear to exert opposing effects on ethmoid plate development. Zebrafish larvae treated with $100 \mathrm{mM}(0.6 \%)$ ethanol showed a reduced ethmoid plate width, which was rescued by a low dose ( $1 \mathrm{nM})$ of exogenous $\mathrm{RA}$. In the same study, RA addition without alcohol exposure resulted in a wider ethmoid plate (Marrs et al., 2010). Disruption of RA signaling appears to be a distinct mechanism of alcohol teratogenesis and is an example of an ExE interaction.

\section{Folic Acid}

Recommendations are given to pregnant women to commence vitamin $\mathrm{B}_{9}$ or folic acid (FA) supplementation prior to conception (WHO) $)^{5}$. FA is converted to folate in the body and prevents neural tube defects such as spina bifida, anencephaly and craniorachischisis. FA was also shown to reduce CLP risk in a meta-analysis (Wilson et al., 2015; Millacura et al., 2017). Still, findings are contradictory as specific genetic predisposing factors combined with FA supplementation were reported to be detrimental to development (Marean et al., 2011). FA is required for nucleic acid synthesis and for histone and DNA methylation. Zebrafish embryos starved of folate showed defects early in development, which may be caused by cell cycle delay in the S-phase (Lee et al., 2012). Upon alcohol exposure during pregnancy, inefficient maternal-to-fetal FA transport leads to FA deficiency in the fetus. This is thought to result from reduced expression of folate binding and transport proteins under the influence of ethanol (Hutson et al., 2012). In zebrafish, FA supplementation rescued ethanolinduced craniofacial malformations most effectively when administered during early embryogenesis (6 hpf). Upon addition of FA, apoptosis in the embryos was reduced and tbx-1 signaling was partially restored (Jiang et al., 2020). Notably, mutations of TBX-1 have been associated with cleft palate in humans (Herman et al., 2012). The rescue by FA may be mediated by its antioxidant properties and epigenetic restoration of ethanol-induced effects (Muralidharan et al., 2015). The role of FA in birth defect prevention is well-characterized. However, future zebrafish studies may offer more insights into genetic predisposing factors that diminish the efficacy of FA to prevent congenital abnormalities (Marean et al., 2011).

\section{PHARMACEUTICALS AND TERATOGENESIS IN ZEBRAFISH LARVAE}

Use of pharmaceuticals during pregnancy can lead to craniofacial malformations. The FDA provides contraindications to pregnant women for the use of drugs associated with teratogenic effects. However, since pregnancies may be unplanned and/or

\footnotetext{
${ }^{5}$ www.who.int/elena/titles/guidance_summaries/daily_iron_pregnancy/en/
}

undetected in the first months, it is not always possible to cease use of medication during early pregnancy (Finer and Zolna, 2016). Pharmaceuticals are a prime example of highly controllable environmental factors, as circulating doses in patients are standardized. By using equivalent doses in animal studies, direct comparisons of teratogenic effects can be made between species. In zebrafish, administration of drugs is relatively simple, but care should be taken to minimize effects of embryo medium conditions such as $\mathrm{pH}$, salt concentration and temperature on drug uptake (Weigt et al., 2011).

For example, the widely used anti-epileptic drug and mood stabilizer VPA, prescribed to women of reproductive age, is frequently associated with craniofacial teratogenicity. VPA was reported to cause FVSP, with symptoms such as intellectual disability, facial abnormalities (including CLP) and cardiac defects (Clayton-Smith et al., 2019). VPA acts by inhibition of histone deacetylases, which results in changed expression of genes important for craniofacial development (Phiel et al., 2001; Gurvich et al., 2005). Altered WNT signaling is a known mechanism of VPA teratogenesis. Impaired WNT signaling by genetic or environmental causes is known to result in craniofacial malformations such as CLP in humans. For a comprehensive overview on the involvement of the WNT pathway in craniofacial development we refer to a previous review (Reynolds et al., 2019).

The reported phenotypic effects of VPA on zebrafish vary between studies. However, parallels between human FVSP and zebrafish phenotypes can be drawn. VPA exposure between 4 and $96 \mathrm{hpf}(30 \mu \mathrm{M})$ resulted in microcephaly, a shortened ethmoid plate with rough anterior edge, and a hypoplastic Meckel's cartilage with disorganized chondrocyte stacking (Liu et al., 2020). These effects on the ethmoid plate parallel those of the cleft palate phenotype in FVSP. In our lab, early (1-13 hpf) and late (25-37 hpf) embryonic VPA exposure (50 and 100 $\mu \mathrm{M}$ VPA) resulted in a shortened head, reduced bone formation and smaller ceratohyals. Wnt marker axin 2 was downregulated, while the Wnt inhibitor $d k k 1 b$ was upregulated at $5 \mathrm{dpf}$. This may account for the decreased ossification, as Wnt is essential in initiating ossification (Gebuijs et al., 2020). Martinez and colleagues reported on a dramatic decrease of survival and lack of development of the craniofacial cartilages in embryos exposed to 25,50 , and $100 \mu \mathrm{M}$ at $4-96 \mathrm{hpf}$. The long exposure window used in this study may account for the phenotypic discrepancy with the results obtained in our lab.

In addition to VPA, many other drugs may affect craniofacial development. Obviously, the effects depend on the dose as well as on the exposure duration or corresponding developmental stage. A succinct, tabular overview of effects and mechanisms of selected teratogens from major drug classes is provided in Table 1. We systematically compared the effects reported in zebrafish with phenotypes described in humans (or if not available, in mouse models). Zebrafish models largely mimicked the phenotypic effects that were observed in mammals, and especially humans, in six out of eight selected teratogens from various drug classes. The target mechanisms implicated in craniofacial development largely varied, but in three cases 
TABLE 1 | Reported effects of pharmaceuticals at various concentrations and exposure times on zebrafish craniofacial development and parallel craniofacial findings in humans or, if not available, in mice.

\begin{tabular}{|c|c|c|c|c|c|c|}
\hline Compound & Concentration & Exposure time & Effects in zebrafish & References & $\begin{array}{l}\text { Target mechanisms in craniofacial } \\
\text { development }\end{array}$ & Effects on mammals \\
\hline $\begin{array}{l}\text { Phenytoin } \\
\text { (Anti-epileptic) }\end{array}$ & $200 \mu \mathrm{M}$ & 4-96 hpf & $\begin{array}{l}\text { Irregular anterior ethmoid border and } \\
\text { rounder cells, shortened head }\end{array}$ & Liu et al., 2020 & $\begin{array}{l}\text { Upregulated retinoic acid receptorsand } \\
\text { growth factors IGF-2, TGFa, and } \\
\text { TGFb1, (Gelineau-van Waes et al., } \\
\text { 1999) }\end{array}$ & $\begin{array}{l}\text { Causes fetal Hydantoinsyndrome with } \\
\text { microcephaly cleft lip and/or cleft } \\
\text { palate in humans (Gelineau-van Waes } \\
\text { et al., 1999). In mice cleft lip and palate } \\
\text { (Sulik et al., 1979; Mao and Tang, 2010) }\end{array}$ \\
\hline Warfarin (Anticoagulant) & $52.4 \mu \mathrm{M}$ & 2.5-72 hpf & $\begin{array}{l}\text { Severe head malformations } \\
\text { (unspecified), eye and otolith defects }\end{array}$ & Weigt et al., 2012 & $\begin{array}{l}\text { Upregulated Bmp antagonist tsku. } \\
\text { Inhibited glutamyl to } \gamma \text {-carboxyglutamyl } \\
\text { transition of vitamin K-dependent } \\
\text { proteins such as osteocalcin and } \\
\text { periostin (Hanumanthaiah et al., 2001; } \\
\text { Fernandez et al., 2014) }\end{array}$ & $\begin{array}{l}\text { Craniofacial malformations of the nose } \\
\text { and airways, eye/ear defects and cleft } \\
\text { lip in humans when taken during the } \\
\text { first trimester of gestation (Hou, 2004) }\end{array}$ \\
\hline
\end{tabular}

$60 \mu \mathrm{M} \quad 4-96 \mathrm{hpf} \quad \begin{aligned} & \text { Shortened head structures, a dent in } \\ & \text { the anterior ethmoid plate, which also }\end{aligned}$

the anterior ethmoid plate, which also showed altered cell morphology and disorganized cell stacking

Methotrexate $\quad 100-200 \mu \mathrm{M} \quad 4-96 \mathrm{hpf}$
(Immunosuppressor)

Size reduction of the neurocranium, $\begin{array}{ll}\text { (Immunosuppressor) } & \begin{array}{l}\text { micro clefts in the anterior ethmoid } \\ \text { plate. Cells that make up the ethmoid }\end{array}\end{array}$ plate appeared disorganized

$\begin{array}{lll}\begin{array}{l}\text { Acetaminophen } \\ \text { (Paracetamol) }\end{array} & 2.5-13.4 \mathrm{mM} & 0-120 / 72-120 \\ \begin{array}{l}\text { Cyclosporin A } \\ \text { (Immunmodulator) }\end{array} & 10 \mu \mathrm{M} & 8-120 \mathrm{hpf} \\ & & \\ \begin{array}{l}\text { Hydroxyurea (Sickle-cell } \\ \text { anemia and psoriasis) }\end{array} & 1 \mathrm{mM} & 4-96 \mathrm{hpf} \\ \begin{array}{l}\text { Leflunomide } \\ \text { (Anit-rheumatic drug) }\end{array} & 10 \mu \mathrm{M} & 8-120 \mathrm{hpf} \\ & 10 \mu \mathrm{M} & 8-24 \mathrm{hpf} \\ & 4-96 \mathrm{hpf}\end{array}$

Palatoquadral length, ceratohyal length and head size reduced

Hypoplasia of the ceratohyoids and ceratobranchials, and reduced cartilage formation in of the viscerocranium

(Corticosteroid)

Shortening of the head resembling micrognathia and microcephaly

Craniofacial cartilages did not form

Lee et al., 2013; et al., 2020

Folic acid antagonist which inhibits DNA synthesis and cell proliferation by competitively inhibiting dihydrofolate reductase (Lee et al., 2012)

Cedron et al., 2020 Activation cytochrome P450 and increased apoptosis (Cedron et al., 2020)

Seda et al., 2019 Inhibitor of calcineurin, which dephosphorylates transcription factors Nuclear factor of activated T-cells, upon which these enter the cell nucleus and drive transcription (Winslow et al., 2006) Largely unknown. Ribonucleotide reductase inhibitor, by which DNA synthesis is inhibited (Woo et al., 2004) Inhibitor of Dihydroorotate dehydrogenase (DHODH) (Pinto and Dougados, 2006)

Increase in the ceratohyal angle

Shortening of the head region and rough edge to the anterior ethmoid plate and round, small chondrocytes

Seda et al., 2019 Liu et al., 2020

Increase of matrix metalloproteinase 2 and 9 expression and activity, trough the glucocorticoid receptor.

Degradation of extracellular matrix components (Hillegass et al., 2008)

Craniosynostosis and microcephaly and incomplete cleft palate in

humans (Granzow et al., 2003; Zarella et al., 2016)

No affected phenotypes reported

Cleft palate in mice (Gasser et al., 1992). Nfatc1-deficient mice exhibit reduced reduced formation of mineralized bone resulting in wider cranial sutures (Winslow et al., 2006)

In mice microcephaly, and hydrocephalus (Woo et al., 2004)

Miller syndrome caused by DHODH gene defects micrognathia cleft palate cleft lip in humans (Ng et al., 2010)

Cleft palate in mice via inhibiting Wnt/ $\beta$-catenin signaling (Hu et al., 2013) 
a direct etiological link with major developmental pathways could be made. Other mechanisms involved direct effects on transcription or DNA synthesis. The translational value as well as the predictive value of the zebrafish model for the study of craniofacial malformations caused by teratogenic pharmaceuticals is demonstrated.

\section{ESTROGENS AND CRANIOFACIAL MALFORMATIONS}

Endocrine disruption in the embryo can occur by the intake of estrogen-resembling chemicals that disrupt estrogen signaling, such as oral contraceptives. Although no effects on craniofacial development have been reported on continued contraceptive pill use during pregnancy, abundant sources of exogenous estrogens in the (house/work) environment are present, for instance in food (Paterni et al., 2017). Estrogen-like compounds in household items can affect craniofacial development and analyzing such exposures in patients is complex. Zebrafish have been used to study the effects of supraphysiological doses of exogenous (xeno) estrogens on craniofacial development (Cohen et al., 2014).

Estrogens are crucial for development and act through nuclear estrogen receptors (ER) alpha and beta, that (hetero and homo) dimerize to form DNA binding domains (Tanko et al., 2008). Additionally, estrogens act by binding to transmembrane G-protein GPR-30, which induces signaling cascades via phospholipase C activation (Tanko et al., 2008). Endogenously, estrogens are synthesized from androgens by aromatase. Estrogens are pivotal for the maintenance of bone and cartilage. This is illustrated by the presence of ER on mesenchymal stem cells during chondrogenesis and the production of estrogens by chondrocytes to stimulate their proliferation (Chagin et al., 2006; Fushimi et al., 2009; Gao et al., 2013).

Zebrafish larvae exposed to exogenous 17ß-estradiol (E2), show dose and developmental stage-dependent craniofacial malformations with enhanced sensitivity during early chondrogenesis (1-2 dpf) (Fushimi et al., 2009). At E2 concentrations of 3-5 $\mu \mathrm{M}$, craniofacial cartilages appeared flattened (Cohen et al., 2014). The angles of the Meckel's and ceratohyal cartilages were widened (Cohen et al., 2014). Below $3 \mu \mathrm{M}$, the length and width of craniofacial structures decreased with increasing concentrations (Cohen et al., 2014). Notably, the inhibition of estrogen biosynthesis with aromatase inhibitors phenocopied these results, exemplifying the requirement for tightly controlled estrogen biosynthesis during chondrogenesis (Cohen et al., 2014).

E2 effects on craniofacial development have been partially attributed to indirect inhibition of Shh signaling through estrogen receptor signaling (Fushimi et al., 2009). E2 impaired the migration of CNCCs into the median ethmoid plate, which resulted in a cleft phenotype (Dougherty et al., 2012). In addition to effects on Shh signaling, E2 resulted in differential expression of other skeletogenic pathway genes in an elaborate investigation of estrogen $(2-5 \mu \mathrm{M})$ effects on zebrafish larval heads (3-7 dpf). Reduced expression of $b m p 2 a$ was reported at 3 dpf. Bmp2a has a crucial function in cartilage and bone formation. Also, the osteoclast differentiation factor rankl was down-regulated at 3 and $4 \mathrm{dpf}$. Further, the inhibitor of the WNT pathway sfrpla was down-regulated at 3 and $4 \mathrm{dpf}$, and the expression of hedgehog receptors ptch 1 and ptch 2 as well as the retinoic acid receptor rarab was decreased throughout development (3-7 dpf). Interestingly, many genes in these pathways were affected differently at 2 and $5 \mu \mathrm{M}$ exposure, while the effects of $2 \mu \mathrm{M}$ were often more dramatic (Pashay Ahi et al., 2016). When using much lower concentrations of E2 $(0.8 \mu \mathrm{M})$ cartilage degradation was observed at $4 \mathrm{dpf}$ and collagen genes were down-regulated at 6 and $7 \mathrm{dpf}(\mathrm{He}$ et al., 2018). In addition, E2 was reported to upregulate Wnt pathways genes such as $w d r 62$ (implicated in microcephaly: OMIM 613583) and wnt11 which has been associated with nonsyndromic CLP. The same study reported upregulation of $f$ stlla, a regulator of Bmp signaling, and upregulation of the Bmp inhibitor nog1, which is implicated in cleft lip etiology. Moreover, Tgfb receptor 1 expression was downregulated. Variations in this gene cause Loey-Dietz syndrome, which includes craniofacial malformations (He et al., 2018). Overall, exogenous E2 had effects on expression of multiple genes that are involved in craniofacial development.

Recently, a number of zebrafish studies have focused on the effects of bisphenols. Bisphenol A (BPA) is an environmental estrogen-like agent. BPA is found in humans in amniotic fluid, placental tissue and umbilical cord blood (Lee et al., 2018). Pregnant women are exposed to BPA via food packaging, dental fillings and inhalation of house dust (Rudel et al., 2003; Vandenberg et al., 2010; Lofroth et al., 2019). BPA binds to the $\mathrm{ER}$, but it can also bind to the thyroid hormone receptor and to the estrogen-related receptor ERR $\gamma$ (Saili et al., 2013). BPA is less potent than E2: similar morphological defects were found in zebrafish with $15 \mu \mathrm{M}$ E2 and $80 \mu \mathrm{M}$ BPA upon exposure between 8 and 120 hpf (Saili et al., 2013). It should be noted that the concentrations used in these studies exceed environmental concentrations. In zebrafish larvae, BPA induced craniofacial malformations by disrupting chondrocyte organization in the pharyngeal structures and inducing apoptosis (Huang et al., 2020). The BPA-based polymer Bis-GMA used in dental fillers decreased palatoquadral length in zebrafish larvae at $10 \mathrm{nM}$, while the palatoquadral-ceratohyal angle was decreased at $1 \mu \mathrm{M}$ (Kramer et al., 2016). It was hypothesized that these effects are caused by ER-mediated altered expression of SHH and BMP pathway genes. Because of emerging evidence of health problems related to bisphenol, the use of BPA was restricted by the European Union.

Upon the reduction of $\mathrm{BPA}$ use, products containing alternative bisphenols including BPF, BPS and BPAF have spiked. Because of structural similarities to BPA, concerns also exist about the estrogenic properties of these compounds. BPF, BPS and BPAF are also identified in food products and house dust. In zebrafish, BPF reportedly resulted in severe craniofacial abnormalities at $20 \mathrm{mg} / \mathrm{L}$. BPS caused malformations above $200 \mathrm{mg} / \mathrm{L}$ in zebrafish, while BPAF produced severe cardiac defects at $1 \mathrm{mg} / \mathrm{L}$ (Moreman et al., 2017). Indeed, the concentrations used in this study also exceed environmental 
BPA concentrations. Future studies on bisphenols with detailed description of phenotypes and realistic exposure concentrations will provide more insight into the mode of action of various bisphenols on craniofacial development.

\section{EXE INTERACTIONS IN HIGH-THROUGHPUT SCREENINGS}

Craniofacial malformations often serve as outcome measures in zebrafish toxicological investigations. This is because the development of craniofacial structures is highly sensitive to perturbation. Many of the environmental factors discussed in this review have also been investigated in toxicological studies, but these studies lacked specific phenotypic and/or mechanistic information. In general, craniofacial abnormalities were regularly reported in compound studies in zebrafish, but without specifically analyzing the affected structures (Weigt et al., 2012; Ellis et al., 2014; Massarsky et al., 2015). Although purely toxicological investigations are beyond the scope of this review, the methodologies employed in this field can also be used in the study of craniofacial malformations.

For example, investigations of the cumulative effects of teratogens (i.e., ExE interactions) within the zebrafish model are increasing in number. Methods to assess the combinatorial effects of two compounds, synergistic or antagonistic, are currently being developed for toxins with effects on skeletal development (Staal et al., 2018; Heusinkveld et al., 2020; Zoupa et al., 2020). For instance, triazoles (fungicides) cause craniofacial malformations through inhibiting RA degradation by CYP26. These toxins with well-known mechanism of action have been used in coexposure experiments with other agricultural fungicides that target different processes in craniofacial development. Thereby it was shown that binary mixture effects can be predicted using dose addition. This refers to adding up the toxicological effects of two chemicals to predict their effect in a mixture (Zoupa et al., 2020). This method may be helpful in further studies on multifactorial environmental exposures such as TPM of (e-cigarette) smoke.

To unify efforts in craniofacial toxicity screenings, standard outcome measures were optimized by Staal et al. (2018). The Meckel's-palatoquadrate (M-PQ) angle (Figure 3) offered a limited variability, proved applicable over wide concentration ranges, and was suitable to assess the effects of chemical mixtures (Cohen et al., 2014; Staal et al., 2018; Zoupa et al., 2020). The M-PQ angle can be translated as a measure for head and jaw deformations, which is affected in craniofacial malformations such as microcephaly and micrognathia. This relatively simple to obtain parameter is especially suitable for high-throughput screenings. It was also proposed to use in further studies in order to enhance inter-study data comparisons. Similarly, options for high-throughput phenotyping of craniofacial mutants by microcomputed tomography (microCT) are rapidly expanding, benefiting from improved resolution and software tools (Pardo-Martin et al., 2013; Charles et al., 2017). In pathophysiological investigations of craniofacial malformations using zebrafish, the techniques discussed above may be used to

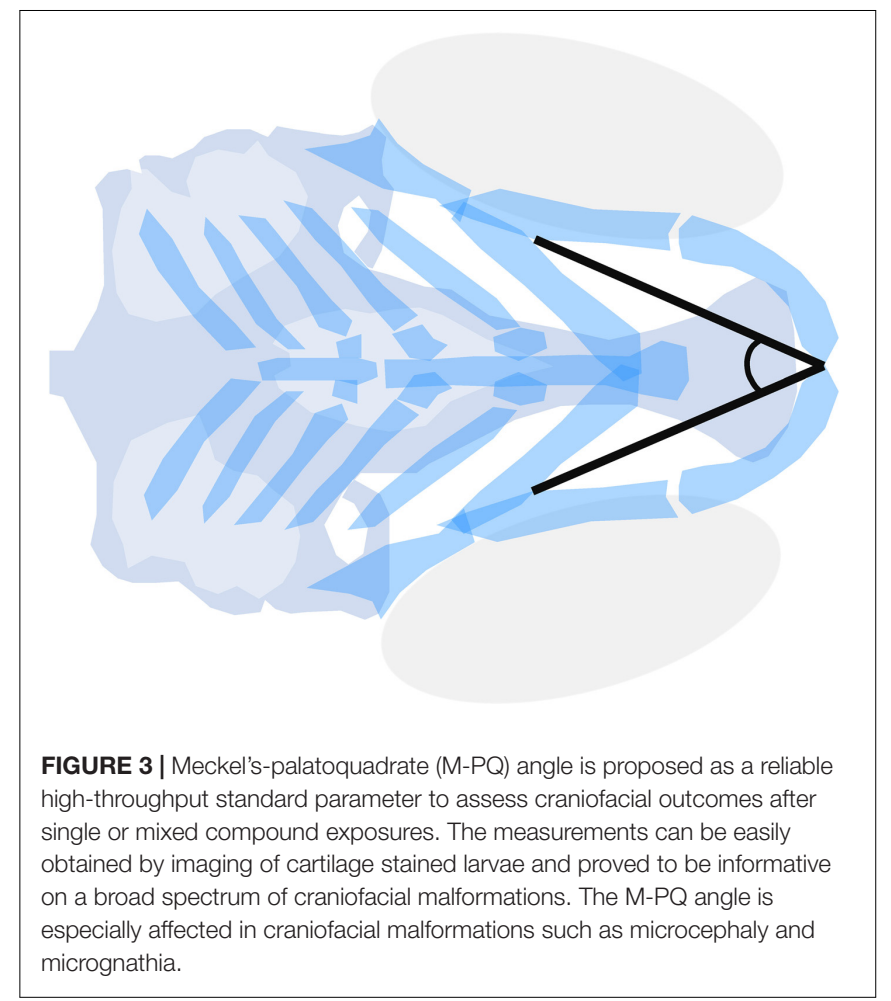

systematically assess, or even predict, the teratogenesis of novel environmental factors.

\section{GENE-ENVIRONMENT INTERACTIONS}

It has become increasingly evident that the effects of environmental exposures during development may be different in individuals with different genotypes. Such interactions of genetic and environmental factors are poorly understood up to now (Lovely et al., 2017). A limited number of zebrafish studies have addressed the interactions between genetic risk factors and environmental factors in the etiology of craniofacial malformations. These studies focused on ethanol sensitivity of zebrafish mutants in FASD research. Screens of n-ethyln-nitrosourea (ENU)-induced mutants and unbiased screens for new candidate genes have been published. Mutants were generally exposed to $1 \%$ ethanol during development. This results in tissue levels between 41 and $51 \mathrm{mM}$, which correlates to blood-alcohol levels after binge drinking events in humans (Zhang et al., 2014). In search of GxE interactions, McCarthy et al. (2013) exposed Pdgfra zebrafish mutants to $1 \%$ ethanol. Loss of PDGFRA in humans has been associated with cleft palate, indicating a direct parallel with zebrafish studies (Rattanasopha et al., 2012). Pdgfra ${ }^{+/-}$zebrafish mutants only developed craniofacial malformations in the presence of ethanol (10-120 hpf) including clefts of the ethmoid plate and breaks in the trabeculae. Moreover, hypoplasia of Meckel's cartilage, the palatoquadrate and the hyosympletics were observed. Pdgfra-/mutants showed enhanced sensitivity to ethanol as the ethmoid 
plate did not form at all, while the sensitivity window was determined at 10-24 hpf. Wildtype embryos exposed to ethanol developed mostly normal in this study with palatal defects only in less than $20 \%$ of the larvae. The protective effect of intact pdgfra against ethanol teratogenesis was shown to be PI3K/mTOR-mediated (McCarthy et al., 2013). This type of in-depth examinations of the mechanisms of action are needed to extrapolate models of gene-environment interactions in craniofacial disorders to clinical use.

Swartz et al. found that mutations of foxi1, hinfp, mars, plk1 and vangl2 also showed increased craniofacial malformations upon exposure to $1 \%$ ethanol compared to wildtypes (Swartz et al., 2014). In particular, ethmoid plate defects were observed in both mars and vangl2 mutants exposed to ethanol. Mars is crucial for protein synthesis as it is involved in tRNA amino acylation. In mars mutants a gap in the posterior ethmoid palate was observed upon ethanol exposure. Vangl2 is a regulator of the planar cell polarity Wnt pathway, and is expressed in the pharyngeal arches. In zebrafish mutants for this gene a narrow, single rod replacing the ethmoid plate was reported as a result of ethanol exposure (Swartz et al., 2014). In humans, VANGL2 is implicated in neural tube defects (Kibar et al., 2011). However, based on the zebrafish study, VANGL2 variations may also be a predisposing factor for cleft palate in case of alcohol use during pregnancy.

The screening of a library of unmapped (unknown alleles) ENU mutants recently identified six new ethanol-sensitive zebrafish mutants (Swartz et al., 2020). The observed malformations in these mutants were highly diverse, which suggests a variety of teratogenic effects of ethanol. One of the mutants was mapped by whole genome sequencing and was validated by targeting the same allele using CRISPR/Cas9 mutagenesis (Swartz et al., 2020). Other mutants of this study remain unmapped, but they seem to be new candidate genes for craniofacial malformations as the specific phenotypes were not previously observed (Swartz et al., 2020). This is a prominent example of why both candidate-based approaches and mutantsensitivity screens are needed in research on GxE interactions. Candidate gene-driven research is focused whereas sensitivity screenings can lead to the discovery of new candidate genes.

The discovery of ethanol-sensitive gene variants in zebrafish shows that the effects of ethanol on craniofacial development may depend on the genetic background. It is highly conceivable this also applies to the teratogenic effect of other compounds. Yet, mechanistic insights into other GxE interactions are still scarce. CLP risks have been associated with genetic sensitivity for specific environmental factors. For instance, TGFA variations may interact with smoking and vitamin deficiency, TGFB3 variations with smoking and alcohol consumption, MTHFR variations with folate intake, RARA with vitamin A intake, and finally GSTT1 and CYP1A variations also with smoking (Stuppia et al., 2011). Zebrafish models are highly suitable to investigate the molecular mechanisms in these geneenvironment interactions.

It is likely that zebrafish craniofacial mutants will be used increasingly to analyze the mechanisms of GxE interactions in the coming years. A number of strategies may be appropriate to approach this. The eminent availability of zebrafish mutants

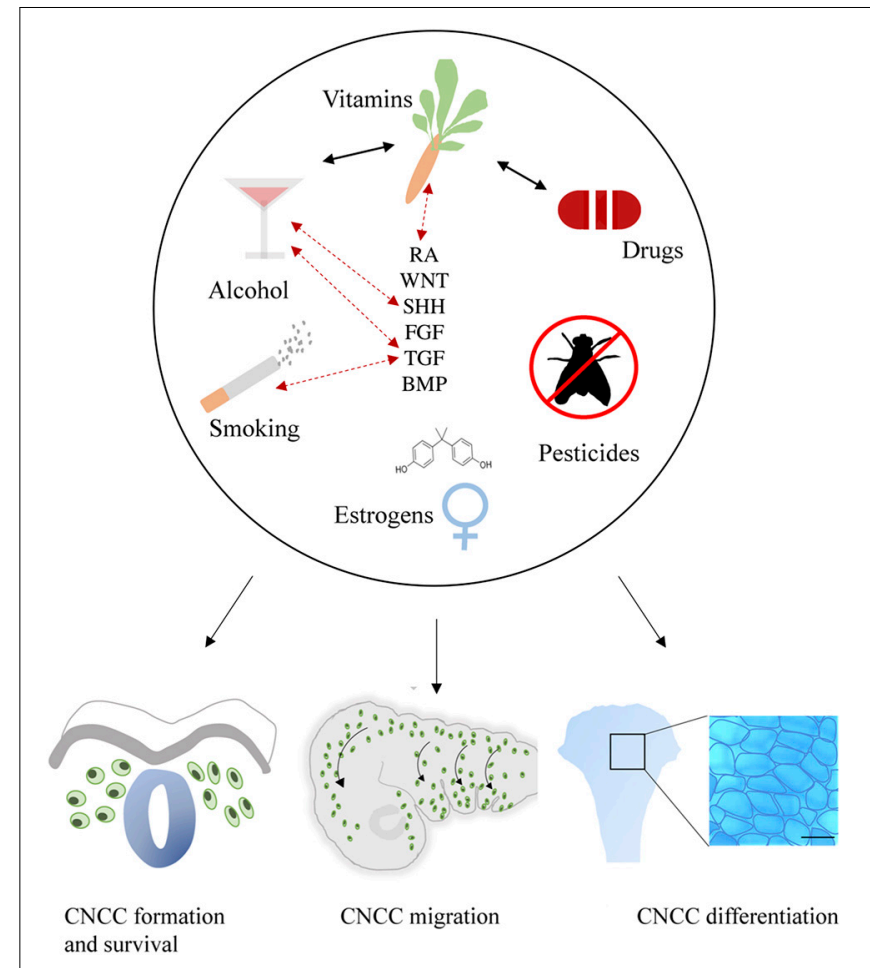

FIGURE 4 | General summary showing the environmental factors smoking, alcohol use, vitamin imbalance, drug use, (xeno) estrogens and pesticides. These factors (represented in the upper part of the figure) differentially affect critical developmental processes such as the formation, survival, delamination, migration, condensation, and differentiation of CNCCs (represented in the lower part of the figure). Evidence of interactions between environmental factors that result in craniofacial malformations has been reported as well, these are indicated by black arrows. Exposure to environmental factors often results in aberrant signaling of essential pathways in craniofacial development including SHH, TGF, FGF, BMP, RA, and WNT. Moreover, gene mutations in these pathways can also interact with environmental factors, complicating the etiology. Known GxE interactions are indicated in this figure with red dotted arrows.

from the zebrafish mutation project $^{6}$ and other sources, will facilitate high-throughput investigations of $\mathrm{GxE}$ interactions on craniofacial development. These efforts can be further optimized by using the broad range of available reporter lines for bone and cartilage formation (Hammond and Moro, 2012). Furthermore, advanced genome editing offers unprecedented opportunities for the investigation of GxE interactions of candidate genes. For instance, the first successful attempt to create loss-of-function alleles for all genes on zebrafish chromosome 1 was recently published, illustrating the astonishing strength of CRISPR/Cas9 techniques (Sun et al., 2019). Systematic gene editing to create zebrafish variants of those observed in human patients could be achieved in the future in view of the increasing success rates of knock-in zebrafish models. These models can be used for highly specific GxE interaction analyses, which may provide predictive data to clinicians.

\footnotetext{
${ }^{6}$ www.sanger.ac.uk/resources/zebrafish/zmp/
} 


\section{CONCLUDING NOTES}

Craniofacial malformations are notorious for their multifactorial etiology including many genetic and environmental factors. CLP and other congenital traits in which GxE interactions play a prominent role, present a problem for the development of adequate preventive measures. Here, evidence from zebrafish studies on the phenotypic outcomes and mechanisms of action of a number of important environmental factors that pregnant women may encounter in daily life is reviewed. It stands out that the mechanisms of action for most of these factors remain incompletely understood, while the phenotypic descriptions vary widely in the amount of details given.

Craniofacial development is a highly sensitive process, which is regulated by major signaling pathways including WNT, BMP, FGF, SHH, and RA. This review substantiates that environmental factors may directly or indirectly affect these pathways and thereby disrupt CNCC formation, survival, migration and differentiation (Figure 4). It is not beyond imagination that multiple environmental factors can be present simultaneously during early pregnancy. Therefore, studies into ExE interactions are highly important.

Zebrafish prove to be a valuable translational model for a wide range of craniofacial malformations, and are also highly suited for identifying the mechanisms of action associated with environmental factors and $\mathrm{GxE}$ interactions. Moreover, zebrafish research will boost the identification and health risk assessment of new teratogens.

Although many health recommendations to prevent craniofacial and other congenital malformations have already

\section{REFERENCES}

Aceto, J., Nourizadeh-Lillabadi, R., Maree, R., Dardenne, N., Jeanray, N., Wehenkel, L., et al. (2015). Zebrafish bone and general physiology are differently affected by hormones or changes in gravity. PLoS One 10:e0126928. doi: 10.1371/journal.pone.0126928

Ackermans, M. M., Zhou, H., Carels, C. E., Wagener, F. A., and Von den Hoff, J. W. (2011). Vitamin A and clefting: putative biological mechanisms. Nutr. Rev. 69, 613-624. doi: 10.1111/j.1753-4887.2011.00425.x

Acum, M., Mastroyannopoulou, K., O’Curry, S., and Young, J. (2020). The psychosocial patient-reported outcomes of end of pathway cleft surgery: a systematic review. Cleft. Palate. Craniofac. J. 57, 990-1007. doi: 10.1177/ 1055665620911328

Al-Ani, A. H., Antoun, J. S., Thomson, W. M., Merriman, T. R., and Farella, M. (2017). Hypodontia: an update on its etiology, classification, and clinical management. Biomed. Res. Int. 2017:9378325.

Ali, S., Champagne, D. L., Alia, A., and Richardson, M. K. (2011). Large-scale analysis of acute ethanol exposure in zebrafish development: a critical time window and resilience. PLoS One 6:e20037. doi: 10.1371/journal.pone.0020037

Andreeva, V., Connolly, M. H., Stewart-Swift, C., Fraher, D., Burt, J., Cardarelli, J., et al. (2011). Identification of adult mineralized tissue zebrafish mutants. Genesis 49, 360-366. doi: 10.1002/dvg.20712

Beaty, T. H., Hetmanski, J. B., Zeiger, J. S., Fan, Y. T., Liang, K. Y., VanderKolk, C. A., et al. (2002). Testing candidate genes for non-syndromic oral clefts using a case-parent trio design. Genet. Epidemiol. 22, 1-11. doi: 10.1002/gepi.1039

Beaty, T. H., Ruczinski, I., Murray, J. C., Marazita, M. L., Munger, R. G., Hetmanski, J. B., et al. (2011). Evidence for Gene-Environment Interaction in a Genome Wide Study of Nonsyndromic Cleft Palate. Genet. Epidemiol. 35, 469-478.

Billiard, S. M., Timme-Laragy, A. R., Wassenberg, D. M., Cockman, C., and Di Giulio, R. T. (2006). The role of the aryl hydrocarbon receptor been implemented by healthcare professionals for years, more research should be done to obtain a more extensive picture of the risks. After all, in the field of environmental exposures there is much to gain as - in theory - all of these factors can be eliminated if public health awareness is increased and risks are adequately identified. A better understanding of environmental teratogens and genetic risk factors will allow for routine screening and a personalized approach in the future. Evidence from zebrafish studies will help to translate preclinical data to practice and will support health recommendations to pregnant women to decrease the risks of CLP and other craniofacial malformations.

\section{AUTHOR CONTRIBUTIONS}

SR wrote the manuscript. JM, FW, and JV conceptualized and revised the manuscript. All authors contributed to the article and approved the submitted version.

\section{FUNDING}

This study was supported by the Radboud University Medical Center and the Dr. Vaillant Foundation.

\section{ACKNOWLEDGMENTS}

We would like to thank Tiffany Ernst for the constructive textual feedback.

pathway in mediating synergistic developmental toxicity of polycyclic aromatic hydrocarbons to zebrafish. Toxicol. Sci. 92, 526-536. doi: 10.1093/toxsci/kfl011 Blader, P., and Strahle, U. (1998). Ethanol impairs migration of the prechordal plate in the zebrafish embryo. Dev. Biol. 201, 185-201. doi: 10.1006/dbio.1998.8995

Bruneel, B., and Witten, P. E. (2015). Power and challenges of using zebrafish as a model for skeletal tissue imaging.Connect. Tissue Res. 56, 161-173. doi: 10.3109/03008207.2015.1013193

Burd, L., Roberts, D., Olson, M., and Odendaal, H. (2007). Ethanol and the placenta: a review. J. Matern. Fetal Neonatal. Med. 20, 361-375.

Burton, D. F., Zhang, C., Boa-Amponsem, O., Mackinnon, S., and Cole, G. J. (2017). Long-term behavioral change as a result of acute ethanol exposure in zebrafish: evidence for a role for sonic hedgehog but not retinoic acid signaling. Neurotoxicol. Teratol. 61, 66-73. doi: 10.1016/j.ntt.2017.01.006

Bush, J. O., and Jiang, R. (2012). Palatogenesis: morphogenetic and molecular mechanisms of secondary palate development. Development 139, 231-243. doi: 10.1242/dev.067082

Carmichael, S. L., Ma, C., Rasmussen, S. A., Honein, M. A., Lammer, E. J., Shaw, G. M., et al. (2008). Craniosynostosis and maternal smoking. Birth Defects Res. A. Clin. Mol. Teratol. 82, 78-85.

Carvan, M. J. III, Loucks, E., Weber, D. N., and Williams, F. E. (2004). Ethanol effects on the developing zebrafish: neurobehavior and skeletal morphogenesis. Neurotoxicol. Teratol. 26, 757-768. doi: 10.1016/j.ntt.2004.06.016

Cedron, V. P., Weiner, A. M. J., Vera, M., and Sanchez, L. (2020). Acetaminophen affects the survivor, pigmentation and development of craniofacial structures in zebrafish (Danio rerio) embryos. Biochem. Pharmacol. 174:113816. doi: 10.1016/j.bcp.2020.113816

Chagin, A. S., Chrysis, D., Takigawa, M., Ritzen, E. M., and Savendahl, L. (2006). Locally produced estrogen promotes fetal rat metatarsal bone growth; an effect mediated through increased chondrocyte proliferation and decreased apoptosis. J. Endocrinol. 188, 193-203. doi: 10.1677/joe.1.06364 
Charles, J. F., Sury, M., Tsang, K., Urso, K., Henke, K., Huang, Y., et al. (2017). Utility of quantitative micro-computed tomographic analysis in zebrafish to define gene function during skeletogenesis. Bone 101, 162-171. doi: 10.1016/ j.bone.2017.05.001

Chawla, B., Swain, W., Williams, A. L., and Bohnsack, B. L. (2018). Retinoic acid maintains function of neural crest-derived ocular and craniofacial structures in adult zebrafish. Invest. Ophthalmol. Vis. Sci. 59, 1924-1935. doi: 10.1167/iovs. 17-22845

Chiquet, B. T., Blanton, S. H., Burt, A., Ma, D., Stal, S., Mulliken, J. B., et al. (2008). Variation in WNT genes is associated with non-syndromic cleft lip with or without cleft palate. Hum. Mol. Genet. 17, 2212-2218. doi: 10.1093/hmg/ ddn 121

Clayton-Smith, J., Bromley, R., Dean, J., Journel, H., Odent, S., Wood, A., et al. (2019). Diagnosis and management of individuals with Fetal Valproate Spectrum Disorder; a consensus statement from the european reference network for congenital malformations and intellectual disability. Orphanet. J. Rare Dis. 14:180.

Cohen, S. P., LaChappelle, A. R., Walker, B. S., and Lassiter, C. S. (2014). Modulation of estrogen causes disruption of craniofacial chondrogenesis in Danio rerio. Aquat. Toxicol. 152, 113-120. doi: 10.1016/j.aquatox.2014.03.028

Cornille, M., Dambroise, E., Komla-Ebri, D., Kaci, N., Biosse-Duplan, M., Di Rocco, F., et al. (2019). Animal models of craniosynostosis. Neurochirurgie 65, 202-209. doi: 10.1016/j.neuchi.2019.09.010

Cubbage, C. C., and Mabee, P. M. (1996). Development of the cranium and paired fins in the zebrafish Danio rerio (Ostariophysi. Cyprinidae). J. Morphol. 229, 121-160. doi: 10.1002/(sici)1097-4687(199608)229:2<121::aid-jmor1>3.0.co; $2-4$

DeRoo, L. A., Wilcox, A. J., Drevon, C. A., and Lie, R. T. (2008). First-trimester maternal alcohol consumption and the risk of infant oral clefts in Norway: a population-based case-control study. Am. J. Epidemiol. 168, 638-646. doi: 10.1093/aje/kwn186

Dixon, M. J., Marazita, M. L., Beaty, T. H., and Murray, J. C. (2011). Cleft lip and palate: understanding genetic and environmental influences. Nat. Rev. Genet. 12, 167-178. doi: 10.1038/nrg2933

Dougherty, M., Kamel, G., Grimaldi, M., Gfrerer, L., Shubinets, V., Ethier, R., et al. (2013). Distinct requirements for wnt9a and irf6 in extension and integration mechanisms during zebrafish palate morphogenesis. Development 140, 76-81. doi: $10.1242 /$ dev.080473

Dougherty, M., Kamel, G., Shubinets, V., Hickey, G., Grimaldi, M., and Liao, E. C. (2012). Embryonic fate map of first pharyngeal arch structures in the sox10: kaede zebrafish transgenic model. J. Craniofac Surg. 23, 1333-1337. doi: $10.1097 /$ scs.0b013e318260f20b

Duncan, K. M., Mukherjee, K., Cornell, R. A., and Liao, E. C. (2017). Zebrafish models of orofacial clefts. Dev. Dyn. 246, 897-914. doi: 10.1002/dvdy.24566

Eames, B. F., DeLaurier, A., Ullmann, B., Huycke, T. R., Nichols, J. T., Dowd, J., et al. (2013). FishFace: interactive atlas of zebrafish craniofacial development at cellular resolution. BMC Dev. Biol. 13:23. doi: 10.1186/1471-213X-13-23

Eason, J., Williams, A. L., Chawla, B., Apsey, C., and Bohnsack, B. L. (2017). Differences in neural crest sensitivity to ethanol account for the infrequency of anterior segment defects in the eye compared with craniofacial anomalies in a zebrafish model of fetal alcohol syndrome. Birth Defects Res. 109, 1212-1227. doi: 10.1002/bdr2.1069

Ellies, D. L., Langille, R. M., Martin, C. C., Akimenko, M. A., and Ekker, M. (1997). Specific craniofacial cartilage dysmorphogenesis coincides with a loss of dlx gene expression in retinoic acid-treated zebrafish embryos. Mech. Dev. 61, 23-36. doi: 10.1016/s0925-4773(96)00616-8

Ellis, L. D., Soo, E. C., Achenbach, J. C., Morash, M. G., and Soanes, K. H. (2014). Use of the zebrafish larvae as a model to study cigarette smoke condensate toxicity. PLoS One 9:e115305. doi: 10.1371/journal.pone.0115305

Facciol, A., Tsang, B., and Gerlai, R. (2019). Alcohol exposure during embryonic development: an opportunity to conduct systematic developmental time course analyses in zebrafish. Neurosci. Biobehav. Rev. 98, 185-193. doi: 10.1016/j. neubiorev.2019.01.012

Ferdous, J., Mukherjee, R., Ahmed, K. T., and Ali, D. W. (2017). Retinoic acid prevents synaptic deficiencies induced by alcohol exposure during gastrulation in zebrafish embryos. Neurotoxicology 62, 100-110. doi: 10.1016/j.neuro.2017. 05.011
Fernandes, Y., Rampersad, M., Jones, E. M., and Eberhart, J. K. (2019). Social deficits following embryonic ethanol exposure arise in post-larval zebrafish. Addict. Biol. 24, 898-907. doi: 10.1111/adb.12649

Fernandez, I., Santos, A., Cancela, M. L., Laize, V., and Gavaia, P. J. (2014). Warfarin, a potential pollutant in aquatic environment acting through Pxr signaling pathway and gamma-glutamyl carboxylation of vitamin K-dependent proteins. Environ. Pollut. 194, 86-95. doi: 10.1016/j.envpol.2014.07.015

Finer, L. B., and Zolna, M. R. (2016). Declines in unintended pregnancy in the United States, 2008-2011. N. Engl. J. Med. 374, 843-852. doi: 10.1056/ nejmsa1506575

Fushimi, S., Wada, N., Nohno, T., Tomita, M., Saijoh, K., Sunami, S., et al. (2009). 17beta-Estradiol inhibits chondrogenesis in the skull development of zebrafish embryos. Aquat. Toxicol. 95, 292-298. doi: 10.1016/j.aquatox.2009.03.004

Gao, Y., Huang, E., Zhang, H., Wang, J., Wu, N., Chen, X., et al. (2013). Crosstalk between Wnt/beta-catenin and estrogen receptor signaling synergistically promotes osteogenic differentiation of mesenchymal progenitor cells. PLoS One 8:e82436. doi: 10.1371/journal.pone.0082436

Gasser, D. L., Yang, P., and Buetow, K. H. (1992). Palate teratogenicity and embryotoxicity of cyclosporin A in mice. J. Craniofac Genet. Dev. Biol. 12, $155-158$.

Gardner, J. S., Guyard-Boileau, B., Alderman, B. W., Fernbach, S. K., Greene, C., and Mangione, E. J. (1998). Maternal exposure to prescription and nonprescription pharmaceuticals or drugs of abuse and risk of craniosynostosis. Int. J. Epidemiol. 27, 64-67. doi: 10.1093/ije/27.1.64

Gebuijs, I. G. E., Metz, J. R., Zethof, J., Carels, C. E. L., Wagener, F., and Von den Hoff, J. W. (2020). The anti-epileptic drug valproic acid causes malformations in the developing craniofacial skeleton of zebrafish larvae. Mech. Dev. 163:103632. doi: 10.1016/j.mod.2020.103632

Geier, M. C., Chlebowski, A. C., Truong, L., Massey Simonich, S. L., Anderson, K. A., and Tanguay, R. L. (2018). Comparative developmental toxicity of a comprehensive suite of polycyclic aromatic hydrocarbons. Arch. Toxicol. 92, 571-586. doi: 10.1007/s00204-017-2068-9

Gelineau-van Waes, J., Bennett, G. D., and Finnell, R. H. (1999). Phenytoininduced alterations in craniofacial gene expression. Teratology 59, 23-34. doi: 10.1002/(sici)1096-9926(199901)59:1<23::aid-tera7>3.0.co;2-m

Granzow, J. W., Thaller, S. R., and Panthaki, Z. (2003). Cleft palate and toe malformations in a child with fetal methotrexate exposure. J. Craniofac. Surg. 14, 747-748. doi: 10.1097/00001665-200309000-00027

Gurvich, N., Berman, M. G., Wittner, B. S., Gentleman, R. C., Klein, P. S., and Green, J. B. (2005). Association of valproate-induced teratogenesis with histone deacetylase inhibition in vivo. FASEB J. 19, 1166-1168. doi: 10.1096/fj.043425fje

Hammond, C. L., and Moro, E. (2012). Using transgenic reporters to visualize bone and cartilage signaling during development in vivo. Front. Endocrinol. 3:91. doi: $10.3389 /$ fendo.2012.00091

Hanumanthaiah, R., Thankavel, B., Day, K., Gregory, M., and Jagadeeswaran, P. (2001). Developmental expression of vitamin K-dependent gamma-carboxylase activity in zebrafish embryos: effect of warfarin. Blood Cells Mol. Dis. 27, 992-999. doi: 10.1006/bcmd.2001.0472

He, H., Wang, C., Tang, Q., Yang, F., and Xu, Y. (2018). Elucidation of possible molecular mechanisms underlying the estrogen-induced disruption of cartilage development in zebrafish larvae. Toxicol. Lett. 289, 22-27. doi: 10.1016/j.toxlet. 2018.02.023

Herman, S. B., Guo, T., McGinn, D. M., Blonska, A., Shanske, A. L., Bassett, A. S., et al. (2012). Overt cleft palate phenotype and TBX1 genotype correlations in velo-cardio-facial/DiGeorge/22q11.2 deletion syndrome patients. Am. J. Med. Genet. A 158A, 2781-2787.

Heusinkveld, H. J., Schoonen, W. G., Hodemaekers, H. M., Nugraha, A., Sirks, J. J., Veenma, V., et al. (2020). Distinguishing mode of action of compounds inducing craniofacial malformations in zebrafish embryos to support doseresponse modeling in combined exposures. Reprod. Toxicol. 96, 114-127. doi: 10.1016/j.reprotox.2020.06.002

Hillegass, J. M., Villano, C. M., Cooper, K. R., and White, L. A. (2008). Glucocorticoids alter craniofacial development and increase expression and activity of matrix metalloproteinases in developing zebrafish (Danio rerio). Toxicol. Sci. 102, 413-424. doi: 10.1093/toxsci/ $\mathrm{kfn} 010$ 
Holden, L. L., Truong, L., Simonich, M. T., and Tanguay, R. L. (2020). Assessing the hazard of E-Cigarette flavor mixtures using zebrafish. Food Chem. Toxicol. 136:110945. doi: 10.1016/j.fct.2019.110945

Hou, J. W. (2004). Fetal warfarin syndrome.Chang. Gung. Med. J. 27, 691-695.

Howe, K., Clark, M. D., Torroja, C. F., Torrance, J., Berthelot, C., Muffato, M., et al. (2013). The zebrafish reference genome sequence and its relationship to the human genome. Nature 496, 498-503.

Hu, X., Gao, J. H., Liao, Y. J., Tang, S. J., and Lu, F. (2013). Dexamethasone alters epithelium proliferation and survival and suppresses Wnt/beta-catenin signaling in developing cleft palate. Food Chem. Toxicol. 56, 67-74. doi: 10. 1016/j.fct.2013.02.003

Huang, W., Zheng, S., Xiao, J., Liu, C., Du, T., and Wu, K. (2020). Parental exposure to bisphenol A affects pharyngeal cartilage development and causes global transcriptomic changes in zebrafish (Danio rerio) offspring. Chemosphere 249:126537. doi: 10.1016/j.chemosphere.2020.126537

Hutson, J. R., Stade, B., Lehotay, D. C., Collier, C. P., and Kapur, B. M. (2012). Folic acid transport to the human fetus is decreased in pregnancies with chronic alcohol exposure. PLoS One 7:e38057. doi: 10.1371/journal.pone.0038057

Jentink, J., Loane, M. A., Dolk, H., Barisic, I., Garne, E., Morris, J. K., et al. (2010). Valproic acid monotherapy in pregnancy and major congenital malformations. N. Engl. J. Med. 362, 2185-2193. doi: 10.1056/nejmoa0907328

Jiang, Q., Lu, D., Wang, F., Zhang, Y., Cao, L., Gui, Y., et al. (2020). Folic acid supplement rescues ethanol-induced developmental defects in the zebrafish embryos. Acta Biochim. Biophys. Sin. 52, 536-545. doi: 10.1093/abbs/gmaa030

Johansen, A. M., Lie, R. T., Wilcox, A. J., Andersen, L. F., and Drevon, C. A. (2008). Maternal dietary intake of vitamin A and risk of orofacial clefts: a populationbased case-control study in Norway. Am. J. Epidemiol. 167, 1164-1170. doi: 10.1093/aje/kwn035

Joore, J., van der Lans, G. B., Lanser, P. H., Vervaart, J. M., Zivkovic, D., Speksnijder, J. E., et al. (1994). Effects of retinoic acid on the expression of retinoic acid receptors during zebrafish embryogenesis. Mech. Dev. 46, 137-150. doi: 10.1016/0925-4773(94)90082-5

Kennedy, A. E., Kandalam, S., Olivares-Navarrete, R., and Dickinson, A. J. G. (2017). E-cigarette aerosol exposure can cause craniofacial defects in Xenopus laevis embryos and mammalian neural crest cells. PLoS One 12:e0185729. doi: 10.1371/journal.pone.0185729

Kibar, Z., Salem, S., Bosoi, C. M., Pauwels, E., De Marco, P., Merello, E., et al. (2011). Contribution of VANGL2 mutations to isolated neural tube defects. Clin. Genet. 80, 76-82. doi: 10.1111/j.1399-0004.2010.01515.x

Kimmel, C. B., DeLaurier, A., Ullmann, B., Dowd, J., and McFadden, M. (2010). Modes of developmental outgrowth and shaping of a craniofacial bone in zebrafish. PLoS One 5:e9475. doi: 10.1371/journal.pone.0009475

Kimmel, C. B., Miller, C. T., and Moens, C. B. (2001). Specification and morphogenesis of the zebrafish larval head skeleton. Dev. Biol. 233, 239-257. doi: 10.1006/dbio.2001.0201

Kramer, A. G., Vuthiganon, J., and Lassiter, C. S. (2016). Bis-GMA affects craniofacial development in zebrafish embryos (Danio rerio). Environ. Toxicol. Pharmacol. 43, 159-165. doi: 10.1016/j.etap.2016.02.018

Kuchler, E. C., Silva, L. A. D., Nelson-Filho, P., Saboia, T. M., Rentschler, A. M., Granjeiro, J. M., et al. (2018). Assessing the association between hypoxia during craniofacial development and oral clefts. J. Appl. Oral. Sci. 26:e20170234.

Laue, K., Pogoda, H. M., Daniel, P. B., van Haeringen, A., Alanay, Y., von Ameln, S., et al. (2011). Craniosynostosis and multiple skeletal anomalies in humans and zebrafish result from a defect in the localized degradation of retinoic acid. Am. J. Hum. Genet. 89, 595-606. doi: 10.1016/j.ajhg.2011.09.015

Lee, J., Choi, K., Park, J., Moon, H. B., Choi, G., Lee, J. J., et al. (2018). Bisphenol A distribution in serum, urine, placenta, breast milk, and umbilical cord serum in a birth panel of mother-neonate pairs. Sci. Total Environ. 626, 1494-1501. doi: 10.1016/j.scitotenv.2017.10.042

Lee, M. S., Bonner, J. R., Bernard, D. J., Sanchez, E. L., Sause, E. T., Prentice, R. R., et al. (2012). Disruption of the folate pathway in zebrafish causes developmental defects. BMC Dev. Biol. 12:12. doi: 10.1186/1471-213X-12-12

Lee, Y., Kim, Y. H., Yun, J. S., and Lee, C. J. (2013). Valproic acid decreases the proliferation of telencephalic cells in zebrafish larvae. Neurotoxicol. Teratol. 39, 91-99. doi: 10.1016/j.ntt.2013.07.004

Leslie, E. J., Taub, M. A., Liu, H., Steinberg, K. M., Koboldt, D. C., Zhang, Q. Y., et al. (2015). Identification of functional variants for cleft lip with or without cleft palate in or near PAX7. FGFR2, and NOG by Targeted Sequencing of GWAS Loci. Am. J. Hum. Genet. 96, 397-411. doi: 10.1016/j.ajhg.2015. 01.004

Li, Y. X., Yang, H. T., Zdanowicz, M., Sicklick, J. K., Qi, Y., Camp, T. J., et al. (2007). Fetal alcohol exposure impairs Hedgehog cholesterol modification and signaling. Lab. Invest. 87, 231-240. doi: 10.1038/labinvest. 3700516

Liszewski, W., Ritner, C., Aurigui, J., Wong, S. S., Hussain, N., Krueger, W., et al. (2012). Developmental effects of tobacco smoke exposure during human embryonic stem cell differentiation are mediated through the transforming growth factor-beta superfamily member, Nodal. Differentiation 83, 169-178. doi: 10.1016/j.diff.2011.12.005

Liu, S., Narumi, R., Ikeda, N., Morita, O., and Tasaki, J. (2020). Chemical-induced craniofacial anomalies caused by disruption of neural crest cell development in a zebrafish model. Dev. Dyn. 249, 794-815. doi: 10.1002/dvdy.179

Lofroth, M., Ghasemimehr, M., Falk, A., and Vult von Steyern, P. (2019). Bisphenol A in dental materials - existence, leakage and biological effects. Heliyon 5:e01711. doi: 10.1016/j.heliyon.2019.e01711

Loucks, E., and Carvan, M. J. I. I. I. (2004). Strain-dependent effects of developmental ethanol exposure in zebrafish. Neurotoxicol. Teratol. 26, 745755. doi: 10.1016/j.ntt.2004.06.017

Lovely, C., Rampersad, M., Fernandes, Y., and Eberhart, J. (2017). Geneenvironment interactions in development and disease. Wiley Interdiscip. Rev. Dev. Biol. 6:e247.

Lovely, C. B. (2020). Animal models of gene-alcohol interactions. Birth Defects Res. 112, 367-379. doi: 10.1002/bdr2.1623

Machado, R. G., and Eames, B. F. (2017). Using zebrafish to test the genetic basis of human craniofacial diseases. J. Dent. Res. 96, 1192-1199. doi: 10.1177/ 0022034517722776

Mammadova, A., Ackermans, M. M., Bloemen, M., Oostendorp, C., Zhou, H., Carels, C. E., et al. (2014). Effects of retinoic acid on proliferation and gene expression of cleft and non-cleft palatal keratinocytes. Eur. J. Orthod. 36, 727-734. doi: 10.1093/ejo/cjt104

Mansilla, M. A., Kimani, J., Mitchell, L. E., Christensen, K., Boomsma, D. I., Daack-Hirsch, S., et al. (2005). Discordant MZ twins with cleft lip and palate: a model for identifying genes in complex traits. Twin Res. Hum. Genet. 8, 39-46. doi: $10.1375 /$ twin.8.1.39

Mao, X. Y., and Tang, S. J. (2010). Effects of phenytoin on Satb2 and Hoxa2 gene expressions in mouse embryonic craniofacial tissue. Biochem. Cell Biol. 88, 731-735. doi: 10.1139/o10-013

Marean, A., Graf, A., Zhang, Y., and Niswander, L. (2011). Folic acid supplementation can adversely affect murine neural tube closure and embryonic survival. Hum. Mol. Genet. 20, 3678-3683. doi: 10.1093/hmg/ ddr289

Marrs, J. A., Clendenon, S. G., Ratcliffe, D. R., Fielding, S. M., Liu, Q., and Bosron, W. F. (2010). Zebrafish fetal alcohol syndrome model: effects of ethanol are rescued by retinoic acid supplement. Alcohol 44, 707-715. doi: 10.1016/j. alcohol.2009.03.004

Martin, S., McBride, M., McGarry, K., and Hill, C. (2020). Burden of cleft surgery-a 21-year follow-up of patients with cleft lip and palate. Eur. J. Plastic Surg. 43, 365-370. doi: 10.1007/s00238-020-01633-Z

Massarsky, A., Abdel, A., Glazer, L., Levin, E. D., and Di Giulio, R. T. (2017). Exposure to 1,2-Propanediol Impacts Early Development of Zebrafish (Danio rerio) and Induces Hyperactivity. Zebrafish 14, 216-222. doi: 10.1089/zeb.2016. 1400

Massarsky, A., Bone, A. J., Dong, W., Hinton, D. E., Prasad, G. L., and Di Giulio, R. T. (2016). AHR2 morpholino knockdown reduces the toxicity of total particulate matter to zebrafish embryos. Toxicol. Appl. Pharmacol. 309, 63-76. doi: 10.1016/j.taap.2016.08.024

Massarsky, A., Jayasundara, N., Bailey, J. M., Oliveri, A. N., Levin, E. D., Prasad, G. L., et al. (2015). Teratogenic, bioenergetic, and behavioral effects of exposure to total particulate matter on early development of zebrafish (Danio rerio) are not mimicked by nicotine. Neurotoxicol. Teratol. 51, 77-88. doi: 10.1016/j.ntt. 2015.09.006

McCarthy, N., and Eberhart, J. K. (2014). Gene-ethanol interactions underlying fetal alcohol spectrum disorders. Cell Mol. Life. Sci. 71, 2699-2706. doi: 10. 1007/s00018-014-1578-3

McCarthy, N., Wetherill, L., Lovely, C. B., Swartz, M. E., Foroud, T. M., and Eberhart, J. K. (2013). Pdgfra protects against ethanol-induced craniofacial 
defects in a zebrafish model of FASD. Development 140, 3254-3265. doi: 10. $1242 /$ dev.094938

Metzler, M. A., and Sandell, L. L. (2016). Enzymatic metabolism of vitamin A in developing vertebrate embryos. Nutrients 8:812. doi: 10.3390/nu8120812

Millacura, N., Pardo, R., Cifuentes, L., and Suazo, J. (2017). Effects of folic acid fortification on orofacial clefts prevalence: a meta-analysis. Public Health Nutr. 20, 2260-2268. doi: 10.1017/s1368980017000878

Miller, C. T., Schilling, T. F., Lee, K., Parker, J., and Kimmel, C. B. (2000). sucker encodes a zebrafish Endothelin-1 required for ventral pharyngeal arch development. Development 127, 3815-3828.

Moreman, J., Lee, O., Trznadel, M., David, A., Kudoh, T., and Tyler, C. R. (2017). Acute Toxicity, Teratogenic, and Estrogenic Effects of Bisphenol A and its alternative replacements bisphenol S, bisphenol $\mathrm{F}$, and bisphenol AF in Zebrafish Embryo-Larvae. Environ. Sci. Technol. 51, 12796-12805. doi: 10.1021/acs.est.7b03283

Mork, L., and Crump, G. (2015). Zebrafish craniofacial development: a window into early patterning. Curr. Top. Dev. Biol. 115, 235-269. doi: 10.1016/bs.ctdb. 2015.07.001

Muralidharan, P., Sarmah, S., and Marrs, J. A. (2015). Zebrafish retinal defects induced by ethanol exposure are rescued by retinoic acid and folic acid supplement. Alcohol 49, 149-163. doi: 10.1016/j.alcohol.2014.11.001

Ng, S. B., Buckingham, K. J., Lee, C., Bigham, A. W., Tabor, H. K., Dent, K. M., et al. (2010). Exome sequencing identifies the cause of a mendelian disorder. Nat. Genet. 42, 30-35. doi: 10.1038/ng.499

Palpant, N. J., Hofsteen, P., Pabon, L., Reinecke, H., and Murry, C. E. (2015). Cardiac development in zebrafish and human embryonic stem cells is inhibited by exposure to tobacco cigarettes and e-cigarettes. PLoS One 10:e0126259. doi: 10.1371/journal.pone.0126259

Pardo-Martin, C., Allalou, A., Medina, J., Eimon, P. M., Wahlby, C., and Fatih Yanik, M. (2013). High-throughput hyperdimensional vertebrate phenotyping. Nat. Commun. 4:1467.

Parker, B., and Connaughton, V. P. (2007). Effects of nicotine on growth and development in larval zebrafish. Zebrafish 4, 59-68. doi: 10.1089/zeb.2006.9994

Pashay Ahi, E., Walker, B. S., Lassiter, C. S., and Jonsson, Z. O. (2016). Investigation of the effects of estrogen on skeletal gene expression during zebrafish larval head development. PeerJ 4:e1878. doi: 10.7717/peerj.1878

Paterni, I., Granchi, C., and Minutolo, F. (2017). Risks and benefits related to alimentary exposure to xenoestrogens. Crit. Rev. Food Sci. Nutr. 57, 3384-3404. doi: 10.1080/10408398.2015.1126547

Phiel, C. J., Zhang, F., Huang, E. Y., Guenther, M. G., Lazar, M. A., and Klein, P. S. (2001). Histone deacetylase is a direct target of valproic acid, a potent anticonvulsant, mood stabilizer, and teratogen. J. Biol. Chem. 276, 36734-36741. doi: $10.1074 /$ jbc.m101287200

Pinto, P., and Dougados, M. (2006). Leflunomide in clinical practice. Acta Reumatol. Port 31, 215-224.

Rattanasopha, S., Tongkobpetch, S., Srichomthong, C., Siriwan, P., Suphapeetiporn, K., and Shotelersuk, V. (2012). PDGFRa mutations in humans with isolated cleft palate. Eur. J. Hum. Genet. 20, 1058-1062. doi: 10.1038/ejhg.2012.55

Reynolds, K., Kumari, P., Sepulveda, L., Rincon, Gu, R., Ji, Y., et al. (2019). Wnt signaling in orofacial clefts: crosstalk, pathogenesis and models. Dis. Model Mech. 12:dmm037051. doi: 10.1242/dmm.037051

Rocha, M., Singh, N., Ahsan, K., Beiriger, A., and Prince, V. E. (2020). Neural crest development: insights from the zebrafish. Dev. Dyn. 249, 88-111. doi: $10.1002 /$ dvdy. 122

Rudel, R. A., Camann, D. E., Spengler, J. D., Korn, L. R., and Brody, J. G. (2003). Phthalates, alkylphenols, pesticides, polybrominated diphenyl ethers, and other endocrine-disrupting compounds in indoor air and dust. Environ. Sci. Technol. 37, 4543-4553. doi: 10.1021/es0264596

Sabbagh, H. J., Hassan, M. H., Innes, N. P., Elkodary, H. M., Little, J., and Mossey, P. A. (2015). Passive smoking in the etiology of non-syndromic orofacial clefts: a systematic review and meta-analysis. PLoS One 10:e0116963. doi: 10.1371/ journal.pone. 0116963

Saili, K. S., Tilton, S. C., Waters, K. M., and Tanguay, R. L. (2013). Global gene expression analysis reveals pathway differences between teratogenic and nonteratogenic exposure concentrations of bisphenol A and 17beta-estradiol in embryonic zebrafish. Reprod. Toxicol. 38, 89-101. doi: 10.1016/j.reprotox.2013. 03.009
Sampson, P. D., Streissguth, A. P., Bookstein, F. L., Little, R. E., Clarren, S. K., Dehaene, P., et al. (1997). Incidence of fetal alcohol syndrome and prevalence of alcohol-related neurodevelopmental disorder. Teratology 56, 317-326. doi: 10.1002/(sici)1096-9926(199711)56:5<317::aid-tera5>3.0.co;2-u

Sarmah, S., Muralidharan, P., Curtis, C. L., McClintick, J. N., Buente, B. B., Holdgrafer, D. J., et al. (2013). Ethanol exposure disrupts extraembryonic microtubule cytoskeleton and embryonic blastomere cell adhesion, producing epiboly and gastrulation defects. Biol. Open 2, 1013-1021. doi: 10.1242/bio. 20135546

Schilling, T. F., and Kimmel, C. B. (1997). Musculoskeletal patterning in the pharyngeal segments of the zebrafish embryo. Development 124, 2945-2960.

Schober, W., Szendrei, K., Matzen, W., Osiander-Fuchs, H., Heitmann, D., Schettgen, T., et al. (2014). Use of electronic cigarettes (e-cigarettes) impairs indoor air quality and increases FeNO levels of e-cigarette consumers. Int. J. Hyg. Environ. Health 217, 628-637. doi: 10.1016/j.ijheh.2013.11.003

Seda, M., Geerlings, M., Lim, P., Jeyabalan-Srikaran, J., Cichon, A. C., Scambler, P. J., et al. (2019). An FDA-approved drug screen for compounds influencing craniofacial skeletal development and craniosynostosis. Mol. Syndromol. 10, 98-114. doi: 10.1159/000491567

Soares, A. R., Pereira, P. M., Ferreira, V., Reverendo, M., Simoes, J., Bezerra, A. R., et al. (2012). Ethanol exposure induces upregulation of specific microRNAs in zebrafish embryos. Toxicol. Sci. 127, 18-28. doi: 10.1093/toxsci/kfs068

Spoorendonk, K. M., Peterson-Maduro, J., Renn, J., Trowe, T., Kranenbarg, S., Winkler, C., et al. (2008). Retinoic acid and Cyp26b1 are critical regulators of osteogenesis in the axial skeleton. Development 135, 3765-3774. doi: 10.1242/ dev.024034

Staal, Y. C. M., Meijer, J., van der Kris, R. J. C., de Bruijn, A. C., Boersma, A. Y., Gremmer, E. R., et al. (2018). Head skeleton malformations in zebrafish (Danio rerio) to assess adverse effects of mixtures of compounds. Arch. Toxicol. 92, 3549-3564. doi: 10.1007/s00204-018-2320-y

Stuppia, L., Capogreco, M., Marzo, G., La Rovere, D., Antonucci, I., Gatta, V., et al. (2011). Genetics of syndromic and nonsyndromic cleft lip and palate. J. Craniofac Surg. 22, 1722-1726.

Sulik, K. K., Johnston, M. C., Ambrose, L. J., and Dorgan, D. (1979). Phenytoin (dilantin)-induced cleft lip and palate in A/J mice: a scanning and transmission electron microscopic study. Anat. Rec. 195, 243-255. doi: 10.1002/ar. 1091950201

Sun, Y., Zhang, B., Luo, L., Shi, D. L., Wang, H., Cui, Z., et al. (2019). Systematic genome editing of the genes on zebrafish Chromosome 1 by CRISPR/Cas9. Genome Res. 30, 118-126.

Swartz, M. E., Lovely, C. B., McCarthy, N., Kuka, T., and Eberhart, J. K. (2020). Novel ethanol-sensitive mutants identified in an F3 forward genetic screen. Alcohol. Clin. Exp. Res. 44, 56-65. doi: 10.1111/acer.14240

Swartz, M. E., Sheehan-Rooney, K., Dixon, M. J., and Eberhart, J. K. (2011). Examination of a palatogenic gene program in zebrafish. Dev. Dyn. 240, 22042220. doi: $10.1002 /$ dvdy.22713

Swartz, M. E., Wells, M. B., Griffin, M., McCarthy, N., Lovely, C. B., McGurk, P., et al. (2014). A screen of zebrafish mutants identifies ethanol-sensitive genetic loci. Alcohol. Clin. Exp. Res. 38, 694-703. doi: 10.1111/acer.12286

Tanko, L. B., Sondergaard, B. C., Oestergaard, S., Karsdal, M. A., and Christiansen, C. (2008). An update review of cellular mechanisms conferring the indirect and direct effects of estrogen on articular cartilage. Climacteric 11, 4-16. doi: $10.1080 / 13697130701857639$

Tierney, P. A., Karpinski, C. D., Brown, J. E., Luo, W., and Pankow, J. F. (2016). Flavour chemicals in electronic cigarette fluids. Tob Control 25, e10-e15.

Van Otterloo, E., Williams, T., and Artinger, K. B. (2016). The old and new face of craniofacial research: how animal models inform human craniofacial genetic and clinical data. Dev. Biol. 415, 171-187. doi: 10.1016/j.ydbio.2016. 01.017

van Rooij, I. A., Wegerif, M. J., Roelofs, H. M., Peters, W. H., KuijpersJagtman, A. M., Zielhuis, G. A., et al. (2001). Smoking, genetic polymorphisms in biotransformation enzymes, and nonsyndromic oral clefting: a geneenvironment interaction. Epidemiology 12, 502-507. doi: 10.1097/00001648200109000-00007

Vandenberg, L. N., Chahoud, I., Heindel, J. J., Padmanabhan, V., Paumgartten, F. J., and Schoenfelder, G. (2010). Urinary, circulating, and tissue biomonitoring studies indicate widespread exposure to bisphenol A. Environ. Health Perspect 118, 1055-1070. doi: 10.1289/ehp.0901716 
Wada, N., Javidan, Y., Nelson, S., Carney, T. J., Kelsh, R. N., and Schilling, T. F. (2005). Hedgehog signaling is required for cranial neural crest morphogenesis and chondrogenesis at the midline in the zebrafish skull. Development 132, 3977-3988. doi: 10.1242/dev.01943

Wagner, N. J., Camerota, M., and Propper, C. (2017). Prevalence and Perceptions of Electronic Cigarette Use during Pregnancy. Matern. Child Health J. 21, 1655-1661. doi: 10.1007/s10995-016-2257-9

Weigele, J., and Franz-Odendaal, T. A. (2016). Functional bone histology of zebrafish reveals two types of endochondral ossification, different types of osteoblast clusters and a new bone type. J. Anat. 229, 92-103. doi: 10.1111/ joa. 12480

Weigt, S., Huebler, N., Strecker, R., Braunbeck, T., and Broschard, T. H. (2011). Zebrafish (Danio rerio) embryos as a model for testing proteratogens. Toxicology 281, 25-36. doi: 10.1016/j.tox.2011.01.004

Weigt, S., Huebler, N., Strecker, R., Braunbeck, T., and Broschard, T. H. (2012). Developmental effects of coumarin and the anticoagulant coumarin derivative warfarin on zebrafish (Danio rerio) embryos. Reprod. Toxicol. 33, 133-141. doi: 10.1016/j.reprotox.2011.07.001

Williams, A. L., and Bohnsack, B. L. (2019). What's retinoic acid got to do with it? Retinoic acid regulation of the neural crest in craniofacial and ocular development. Genesis 57:e23308. doi: 10.1002/dvg.23308

Wilson, R. D., Genetics, C., Wilson, R. D., Audibert, F., Brock, J. A., Carroll, J., et al. (2015). Pre-conception folic acid and multivitamin supplementation for the primary and secondary prevention of neural tube defects and other folic acid-sensitive congenital anomalies. J. Obstet. Gynaecol. Can. 37, 534-552. doi: 10.1016/s1701-2163(15)30230-9

Winslow, M. M., Pan, M., Starbuck, M., Gallo, E. M., Deng, L., Karsenty, G., et al. (2006). Calcineurin/NFAT signaling in osteoblasts regulates bone mass. Dev. Cell 10, 771-782. doi: 10.1016/j.devcel.2006.04.006

Woo, G. H., Katayama, K., Bak, E. J., Ueno, M., Yamauchi, H., Uetsuka, K., et al. (2004). Effects of prenatal hydroxyurea-treatment on mouse offspring. Exp. Toxicol. Pathol. 56, 1-7. doi: 10.1016/j.etp.2004.04.011

Wu, T., Liang, K. Y., Hetmanski, J. B., Ruczinski, I., Fallin, M. D., Ingersoll, R. G., et al. (2010). Evidence of gene-environment interaction for the IRF6 gene and maternal multivitamin supplementation in controlling the risk of cleft lip with/without cleft palate. Hum. Genet. 128, 401-410. doi: 10.1007/s00439-0100863-y

Xiong, K. M., Peterson, R. E., and Heideman, W. (2008). Aryl hydrocarbon receptor-mediated down-regulation of sox $9 b$ causes jaw malformation in zebrafish embryos. Mol. Pharmacol. 74, 1544-1553. doi: 10.1124/mol.108. 050435

Xuan, Z., Zhongpeng, Y., Yanjun, G., Jiaqi, D., Yuchi, Z., Bing, S., et al. (2016). Maternal active smoking and risk of oral clefts: a meta-analysis. Oral Surg. Oral Med. Oral Pathol. Oral Radiol. 122, 680-690. doi: 10.1016/j.oooo.2016.08.007

Yan, Y. L., Jowett, T., and Postlethwait, J. H. (1998). Ectopic expression of hoxb2 after retinoic acid treatment or mRNA injection: disruption of hindbrain and craniofacial morphogenesis in zebrafish embryos. Dev. Dyn. 213, 370-385. doi: 10.1002/(sici)1097-0177(199812)213:4<370::aid-aja3>3.0.co;2-o

Zarella, C. S., Albino, F. P., Oh, A. K., Wood, B. C., Oluigbo, C. O., Myseros, J. S., et al. (2016). Craniosynostosis following fetal methotrexate exposure. J. Craniofac. Surg. 27, 450-452. doi: 10.1097/scs.0000000000002423

Zhang, C., Frazier, J. M., Chen, H., Liu, Y., Lee, J. A., and Cole, G. J. (2014). Molecular and morphological changes in zebrafish following transient ethanol exposure during defined developmental stages. Neurotoxicol. Teratol. 44, 70-80. doi: 10.1016/j.ntt.2014.06.001

Zhang, H., Yao, Y., Chen, Y., Yue, C., Chen, J., Tong, J., et al. (2016). Crosstalk between $\mathrm{AhR}$ and wnt/beta-catenin signal pathways in the cardiac developmental toxicity of PM2.5 in zebrafish embryos. Toxicology 35, 31-38. doi: 10.1016/j.tox.2016.05.014

Zhu, S. H., Sun, J. Y., Bonnevie, E., Cummins, S. E., Gamst, A., Yin, L., et al. (2014). Four hundred and sixty brands of e-cigarettes and counting: implications for product regulation. Tob. Control 23(Suppl. 3), iii3-iii9.

Zoupa, M., Zwart, E. P., Gremmer, E. R., Nugraha, A., Compeer, S., Slob, W., et al. (2020). Dose addition in chemical mixtures inducing craniofacial malformations in zebrafish (Danio rerio) embryos. Food Chem. Toxicol. 137:111117. doi: $10.1016 /$ j.fct.2020.111117

Conflict of Interest: The authors declare that the research was conducted in the absence of any commercial or financial relationships that could be construed as a potential conflict of interest.

Copyright (c) 2020 Raterman, Metz, Wagener and Von den Hoff. This is an openaccess article distributed under the terms of the Creative Commons Attribution License (CC BY). The use, distribution or reproduction in other forums is permitted, provided the original author(s) and the copyright owner(s) are credited and that the original publication in this journal is cited, in accordance with accepted academic practice. No use, distribution or reproduction is permitted which does not comply with these terms. 